\title{
Experimental Test, Model Validation, and Viability Assessment of a Wave-Rotor Constant-Volume Combustor
}

\author{
M. Razi Nalim ${ }^{1}$ \\ Indiana University - Purdue University, Indianapolis, Indiana, 46202 \\ Philip H. Snyder ${ }^{2}$, \\ Rolls-Royce North American Technologies, Inc. - LibertyWorks ${ }^{T M}$, Indianapolis, Indiana, 46241 \\ and \\ Michael Kowalkowski ${ }^{3}$ \\ Purdue University, West Lafayette, Indiana 47906
}

Design and testing of a wave-rotor constant-volume combustor (WRCVC) achieved stable combustion at near-atmospheric inlet conditions and demonstrated the potential of pressure-gain combustion using a wave rotor. An experiment rig with a motor-driven, room-temperature rotor with large thermal mass operated for short durations within heating limits of extensive in-passage rotating instrumentation. Over 30 successful tests were completed, including a 3-second run amounting to about 2,000 individual firing events. Fast deflagrative combustion was observed with varied ethylene fuel distribution in the passages, showing good combustor operability, insensitive to leakage. Remarkably high flame speeds and a net pressure gain were indirectly indicated from measurements. A time-marching, spatially one-dimensional numerical model of gas dynamics and combustion was used for aero-thermodynamic design, applying loss models previously calibrated with pressure-exchange non-reacting wave-rotor experiments. Major features and trends of the measured gas dynamic and combustion processes showed good agreement with predictions and validated current design methods. Different fuel distributions were tested to better calibrate ignition and combustion sub-models. Simulations illustrate the likely explanations for cases with and without observed ignition, spillage during the filling process, and mixture requirements for consistent torch ignition. The viability of wave rotors for realizing a pressure-gain combustor is discussed.

\footnotetext{
${ }^{1}$ Professor, Department of Mechanical Engineering, Indianapolis. IN. AIAA Associate Fellow. (Corresponding author: mnalim@iupui.edu)

${ }^{2}$ AIAA Member. Currently with Aerodyn Combustion, LLC, Indianapolis. IN.

${ }^{3}$ AIAA Member. Currently with Rolls-Royce Corporation, Indianapolis, IN
}

This is the author's manuscript of the article published in final edited form as: 


\section{Nomenclature}

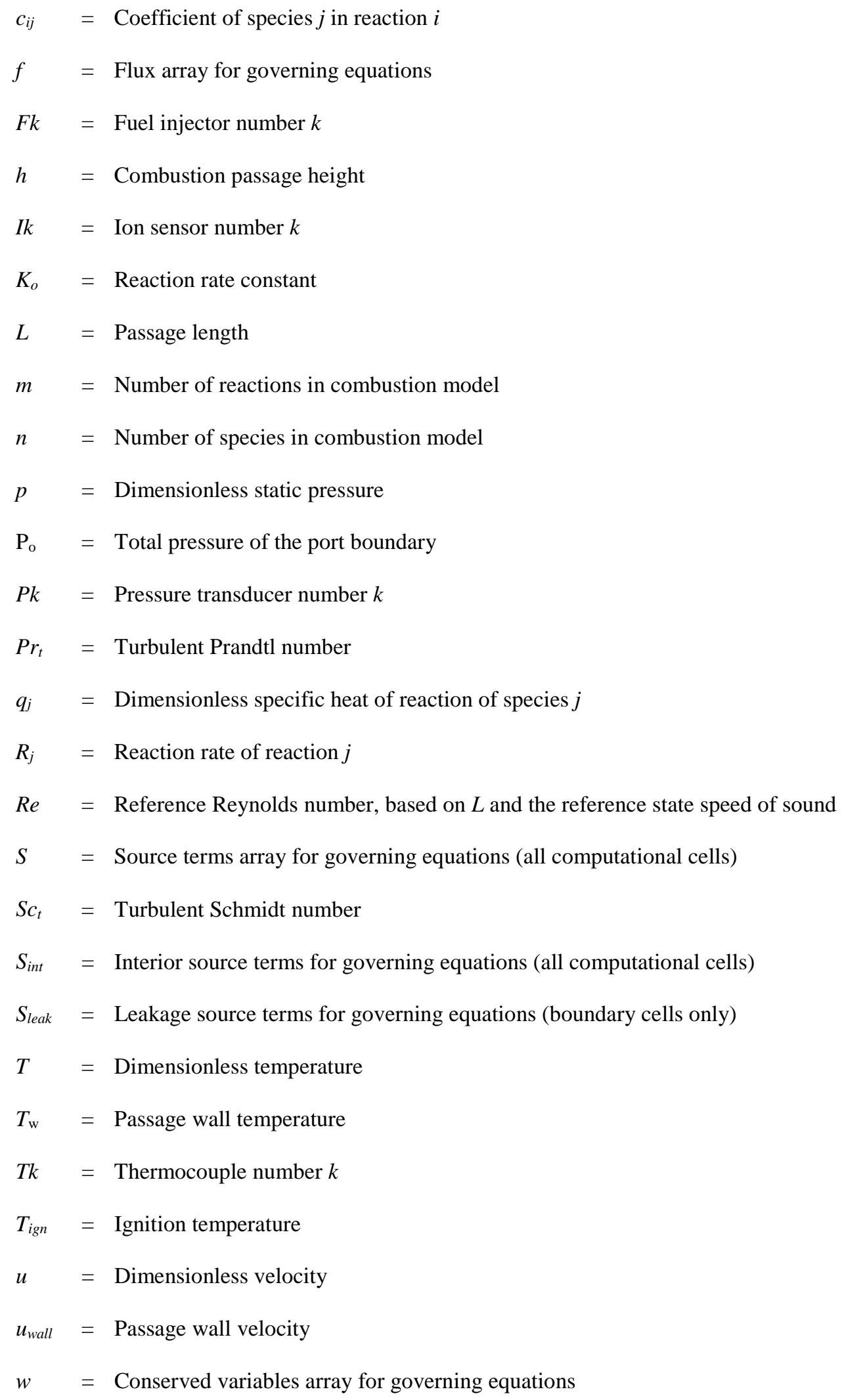




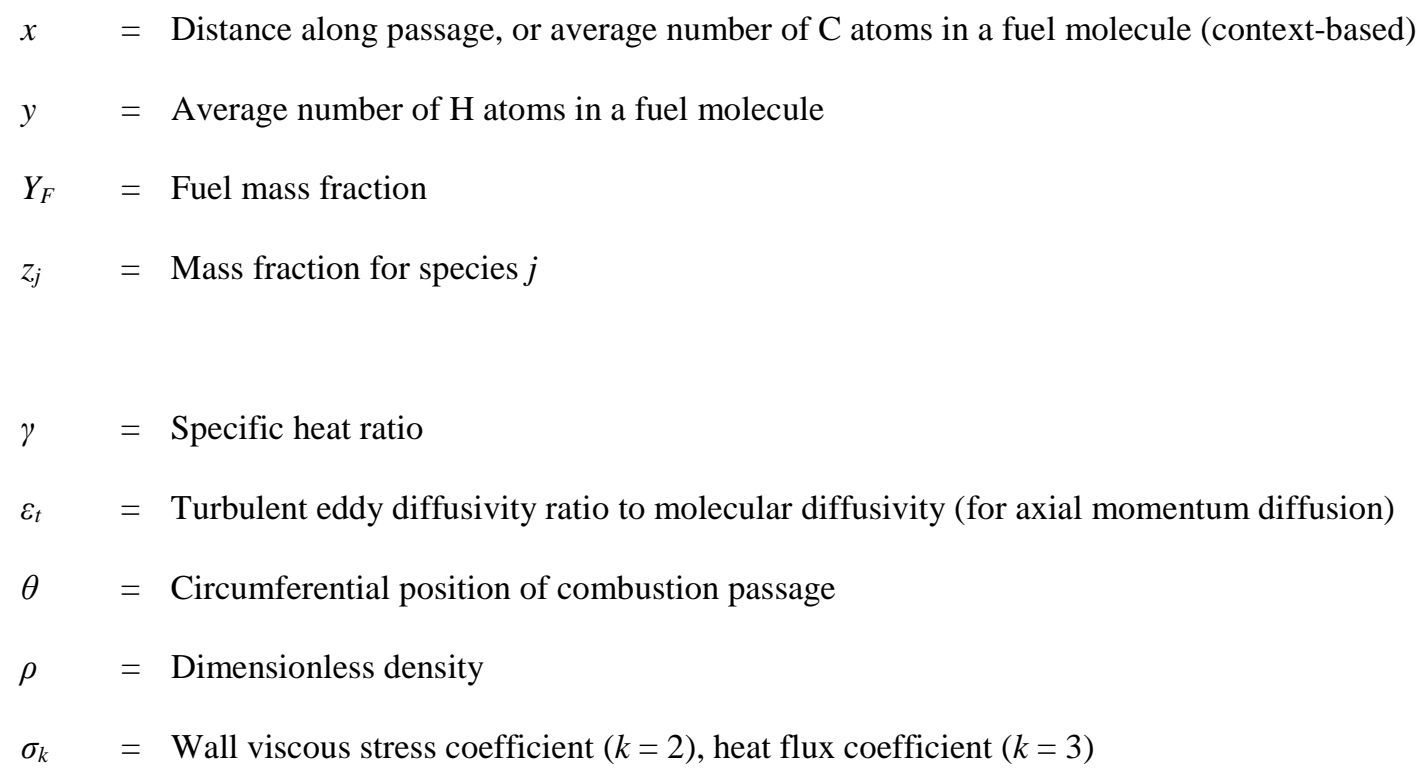

\section{Introduction}

The status quo in today's gas turbine engine is a nominal pressure-loss combustion process. Constant-volume combustion (CVC) systems that accomplish pressure gain have the potential to significantly cut fuel consumption and $\mathrm{CO}_{2}$ emissions of gas turbines, power plants, and propulsion systems. The wave rotor is a promising candidate for implementing CVC mechanically, delivering relatively steady outflow with low inherent losses and high durability. Previously used as dynamic pressure exchangers [1-3] and considered as topping devices for gas turbine engines [3-6], wave rotors have been tested and reported as combustors in one prior test rig [7]. Akbari and Nalim [8,9] provide a detailed reviews of recent developments.

The wave rotor constant-volume combustor (WRCVC) utilizes unsteady wave motion and mechanical confinement to provide pressure gain during combustion. The combustion passages in a WRCVC are arrayed on the periphery of a drum that rotates between two stationary end plates, which house the intake and exit ports. Each passage is periodically charged and discharged as it rotates past partial-annular intake and exit ports located on end walls that function as the intake and exit valves. Premixed air-fuel mixtures flow sequentially, with possibly variable composition, into the rotating combustion passages as they become aligned with the intake port. The passages experience a substantial compression by a traveling shock process before combustion initiation, giving a thermodynamic advantage. When both ends close after charging, the mixture undergoes combustion at nominally 
constant volume when it is ignited, usually by a jet of hot gas at one or both ends (Fig. 1). Combustion must be completed before the passages rotate into alignment with the exit port, initiating the exhaust process. All wave rotors operate on the principle that optimal port location and rotation speed synchronizes valving at both ends and with internal non-steady processes. With a sufficiently large number of passages, there is relatively steady flow of accepted and delivered gases, albeit with some spatial non-uniformity.

The work reported here was intended to demonstrate and investigate cyclic combustion within a wellinstrumented WRCVC, and to evaluate aerothermodynamic design methods and modeling with respect to fuel distrubution, gas dynamics, and ignition. It was not intended to address all mechanical and thermal design requirements of a practical working product. The rig was designed for backward propagation of the combustion flame front, with ignition at only the exit end of the passages. A significant region of the gas near the inlet end is pure air with no fuel, with a combustible mixture nearer to the exit end ignited by a jet of hot gas from a torch igniter, initiating flame propagation from the exit end wall toward the inlet end. To ensure the desired fuel distribution, the passage is typically fully evacuated and refilled in each cycle, and thus does approximate constantvolume combustion. The WRCVC test rig was designed considering both deflagrative $[10,11,12]$ and detonative modes $[13,14]$; the initial tests reported here use only deflagrative combustion. The aerothermal design methods for the WRCVC were based primarily on a one-dimensional transient flow and combustion model. All major loss mechanisms, such as friction, heat transfer, flow incidence, partially open passage-duct flows, shocks, and leakage, are considered in the rig modeling [15-18].

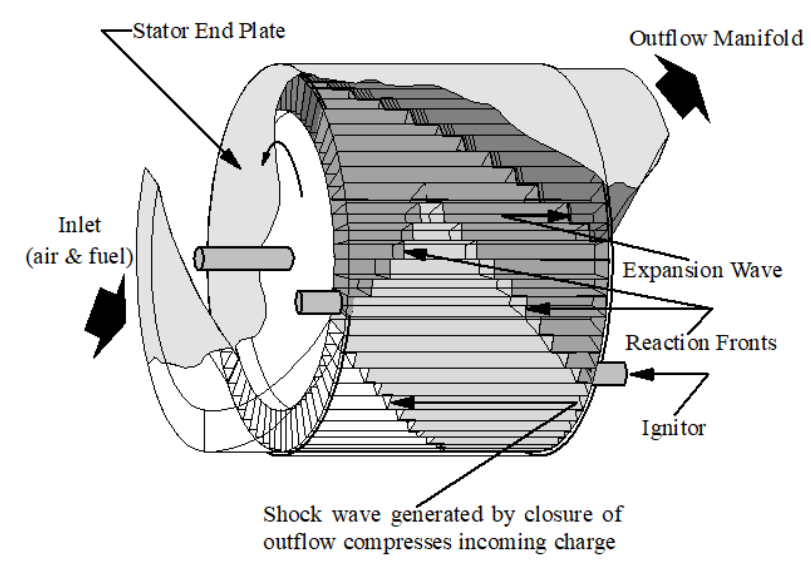

Figure 1 WRCVC schematic [11] 


\section{Wave Rotor Constant Volume Combustor}

\section{A. Experimental Rig}

A wave rotor constant-volume combustor was designed [13,14], built [19], operated [20], and analyzed [18,2127] by an industry-university consortium of the authors' three home institutions. The rotor, 30.95 in. long, consisted of 20 combustion passages separated by 0.1 in. webbing, with radius from 6.48 in. hub to 9.09 in. shroud, so that each combustor has 2.38 in. mean width. Leakage flow between the end plates and the rotor was minimized by their close proximity. Other sealing methods, such as rub seals and brush seals, were considered, but the proximity gap provided a sufficient seal for the initial tests. Leakage flow analysis through a proximity gap of a wave rotor is discussed by Akbari et al [28]. An external casing for leak containment was not installed on the current configuration, leaving the gap exposed to atmosphere.

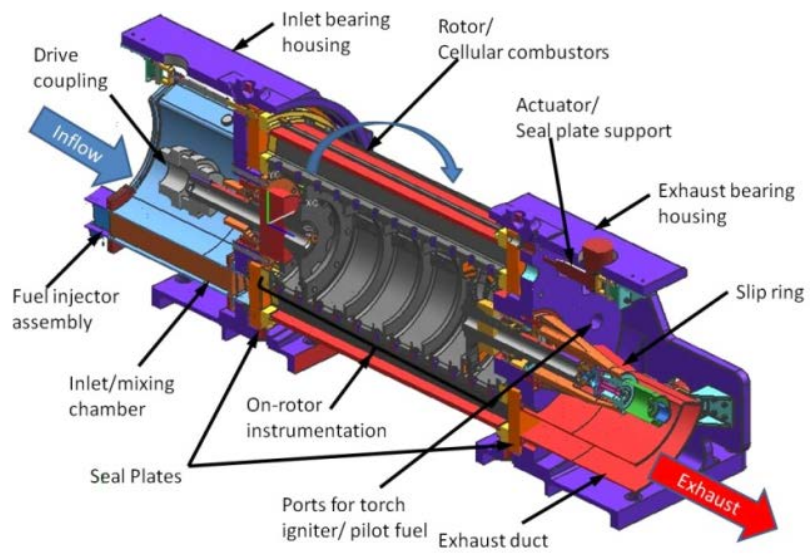

Figure 2 A cut-out view of the WRCVC test rig [20]

The WRCVC test rig was supplied with air at near-ambient temperature and at a pressure adequate to supply a specified flow rate; the exhaust flow was ducted to the outside atmosphere without attempt at pressure recovery or applying back pressure. The main components of the test article were the inlet, exhaust, rotor, seal plates, ignition source, and fuel injectors (Fig. 2). An electrical motor provided rotation with speed control. Gaseous fuels (ethylene and propane) were used in initial testing to avoid vaporization effects and minimize needed mixing time. The porting for initial tests was designed to match an operating speed of $2100 \mathrm{rpm}$ and air flow rates of approximately 10 $\mathrm{lb} / \mathrm{sec}$. At this speed, each passage operates at a frequency of $35 \mathrm{~Hz}$ (cycle time $28 \mathrm{~ms}$ ), while the inlet and exhaust 
ducts will experience weak pulsations at the blade passing frequency of $700 \mathrm{~Hz}$. Short combustion test durations (13 seconds) were chosen to keep the rotor and on-board sensors within their design temperature limits, yet allow hundreds of repeating operating cycles.
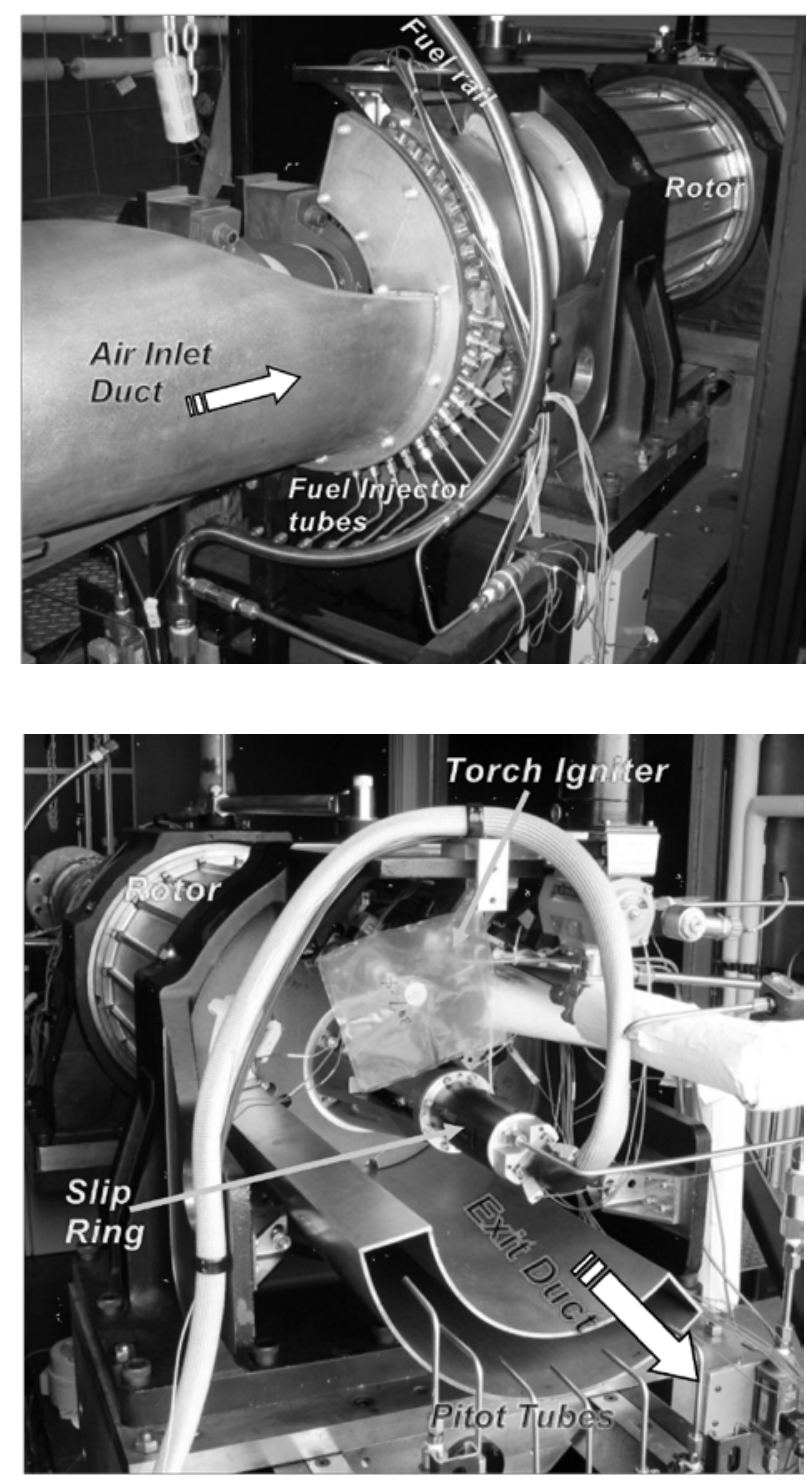

Figure 3 WRCVC inlet duct showing fuel introduction (upper) and exit duct showing Pitot-tube rake (lower)

Photographs of the rig from its two ends are presented in Fig. 3. An unwrapped view of the rotor, connecting ducts, and instrumentation is shown in Fig. 4, in which the $\theta$-axis depicts angular location, with zero corresponding to inlet opening. The exhaust duct was mounted on the opening of the seal plate. It routes the exhaust products away from the test rig and as currently designed does not attempt to capture thermodynamic work available in the exhaust 
gases. The exhaust boundary of the rotor is exposed to ambient conditions. The exhaust port circumferential span is from $-44^{\circ}$ to $75^{\circ}$. The typical distribution of gases in the ducts and passages are shown, with air shaded in blue, unburned fuel-air mixture in green, and burned gas in red.

The air inlet duct upstream of the rotor was mounted on the inlet seal plate. It housed the fuel injectors and inlet guide vanes, and provided adequate mixing length for injected fuel and air. The inlet duct circumferential span is from $0^{\circ}$ to $104^{\circ}$. The inlet opening and closing timings are chosen to match the inflow duration with waves that are generated by the exhaust opening and closing and travel the rotor length. The port overlap $\left(75^{\circ}\right)$ permits full exhaust purging and allows exhaust outflow momentum to induce inflow. Inlet guide vanes turn the flow by $18^{\circ}$ to match the rotor tangential velocity. Thus the inlet flow is ideally axial relative to the passage frame of reference to minimize the incidence losses, which otherwise would contribute to pressure loss and flow separation at the inlet side of the passages. Fifteen fuel injection tubes were evenly spaced at the upstream end of the inlet duct, which has uniform cross sectional shape. Fuel distribution is controlled by the number and location of active fuel injectors. Fuel injection nozzle holes in each tube were located and sized to control cross-flow jet penetration and promote a uniform reactant mixture at the entrance to the rotor.

A propane/air continuous-flow combustor with choked outflow nozzle was developed as the ignition source for the rig [20]. This igniter was mounted on the exhaust end seal plate, providing a hot torch jet that traverses each combustion chamber that moves past the igniter, installed at the $180^{\circ}$ location for the initial tests. The torch igniter chamber was cooled with an air jacket, which provides a film of air coating the interior surface of the igniter nozzle. The torch igniter was designed to operate at approximately one percent of the rig inlet air mass flow.

The passages pictured at an instant in Fig. 4 move upward in this view. The following description of processes occurring in the series of passages depicted at one instant may also be interpreted as the time-history of any single passage. In this depiction, Passage 9 contains generally hot products of combustion at high pressure, while ahead, Passages 8 and 7 are discharging to the exhaust port and experience an expansion wave traveling leftward. Passages 6 through 1 are accepting fresh charge of air and air mixed with fuel, even as Passages 6 through 3 are still also discharging exhaust. With some fuel injection stations F1 through F15 admitting fuel for any given operating condition, the resulting circumferential fuel/air stratification in the intake maps to axial stratification within any given passage. Passages 3 through 1 are continuing to fill while a compression wave generated by closing of the exit end travels leftward. Passages 20 through 17 are awaiting ignition, with combustible mixture at their right end and 
most of the passage, and with only air at the left end. Passage 16 has received hot gas from the torch, and Passages 15 through 10 are experiencing a progression of the combustion phase and gaining pressure. Eventually, successful combustion results in high-pressure gas in Passage 10, consisting of hot combustion product except for some cooler air at the left end. Space-time level plots of key properties are presented in Section V based on combustion and gas dynamic modeling.

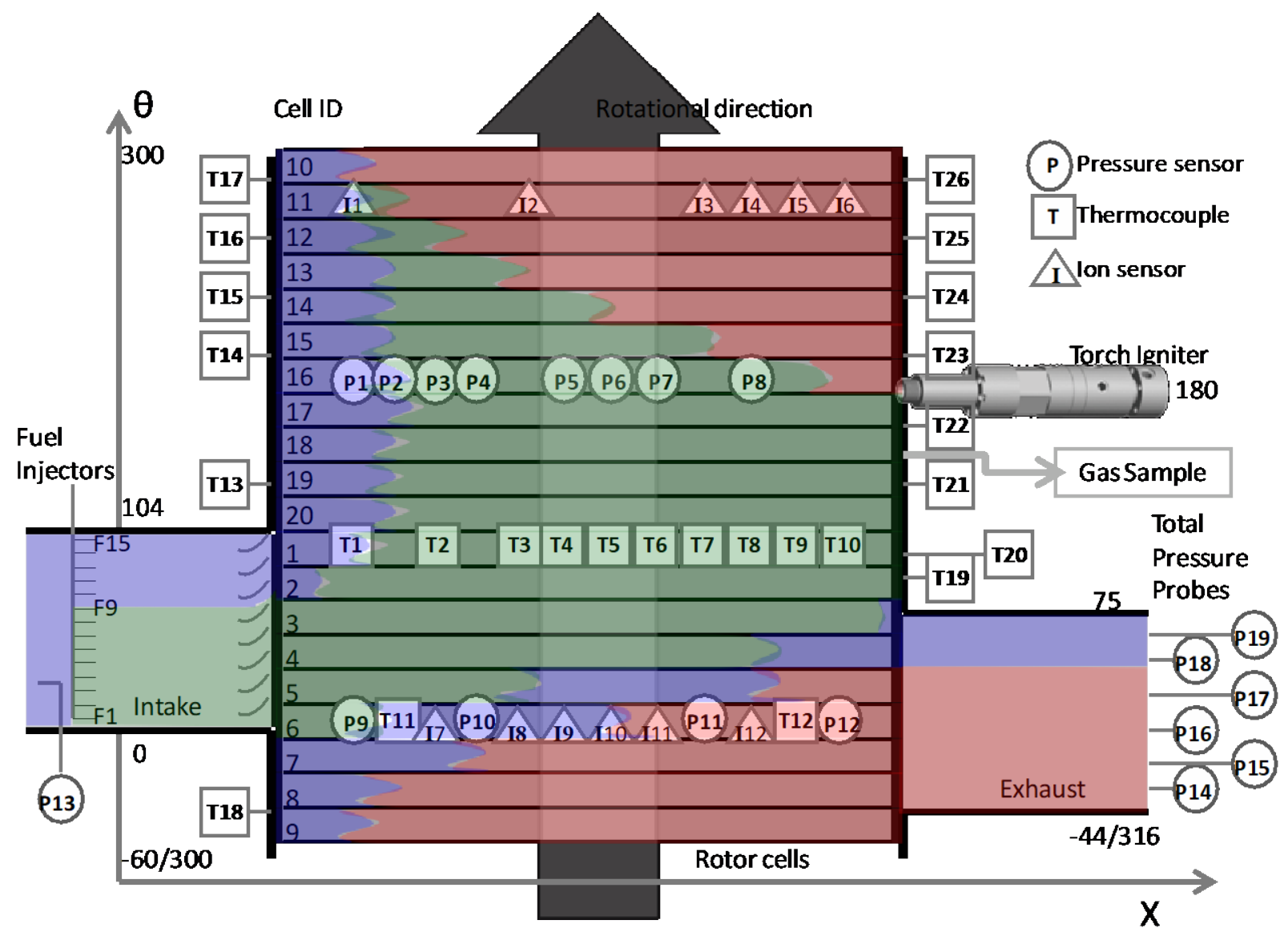

Figure 4 WRCVC unwrapped view: gas distribution, passage identification, igniter location, sensor locations, port spans (in degrees), and fuel injectors [adapted from Ref. 20]

\section{B. Measurements and Data Acquisition}

Four selected combustion passages (Fig. 4 unwrapped view) were instrumented at the inner radius (hub surface) with Type-K thermocouples (T1-T12), high-frequency pressure transducers (P1-P12), and ion probes (I1-I12), with data transferred from the shaft via a slip ring. An incremental encoder connected to a counter card tracks the rotor angular location. The angular data is logged at the same frequency, and triggered at the same time, to precisely 
correlate high frequency data with rotor position. A rake of 6 pitot-tube sensors (P14-P18) installed at the exit duct measured exhaust gas total pressure (Fig. 3, lower). Additional thermocouples (T13-T26) are installed on the left and right stationary end walls, and a gas sampling tube is installed at the exit-side end wall upstream of the igniter location for assessment of near-wall gas mixture properties.

The WRCVC facility included data acquisition and control systems, including a 16-bit data system with 128 main channels logging data at 500 samples per second per channel. This includes all voltage signals from pressure transducers, thermocouples, control feedback devices, accelerometers, and proximity probes. Additionally, 32 channels were dedicated for 12-bit high-frequency data, typically logged at 200,000 samples per second per channel, synchronized with the main channels by a trigger signal. Separate digital and analog control channels are accessed through a custom LabVIEW control panel. The test sequence was automated with better than $1 \mathrm{~ms}$ accuracy, allowing abort criteria on all operational channels. Test operators conducted experiments from a remotely located control room to assure safety.

\section{Test Procedures and Major Observations}

A series of combustion tests were conducted after verifying the operation of the torch igniter and assessing the leakage rate of the test rig. Each test sequence proceeded with rotor spin to target speed, air flow ramp up to targeted flow, torch igniter firing to provide hot jet flow, and then injection of main fuel flow into the inlet air for the planned wave rotor firing duration. Combustion in the rotor passages was maintained, typically for 1-3 s as planned, and the sequence reversed to shut down. The main objective of the initial combustion tests was to map out successful operating conditions with different fuel injection locations and equivalence ratios. In general, the test rig was able to sustain combustion over a wide range of settings. At the optimum operating conditions, the combustor produced a stable steady exhaust plume and operated smoothly throughout ignition and shutdown. A highly repetitive pattern of combustion events was clearly evident.

The tests were performed with rotor clearances intentionally set wide, nearly 0.030 inch, without the use of compensating clearance control features expected in practical applications. The configuration of the cycle keeps any 
leaked hot gas from creating unwanted combustion, evidenced by the operation of the rig without backfire or a flame holding mode of burning in the inlet or exhaust ducts.

Extensive examination of the data provided by the on-rotor instrumentation has answered many questions regarding the initiation of the combustion, the travel of the fuel-air mixture within the passage, and the speed of combustion. A typical test condition corresponded to air flow rate of $9.5 \mathrm{lbm} / \mathrm{sec}$ and $2100 \mathrm{rpm}$ rotor speed. Fuel flow via the first nine fuel injectors (F1-F9) was estimated to create a nominal local equivalence ratio of 1.3 near the right (exit) end of the passage. Pressure measurements are shown in Fig. 5 for one axial location in two different passages as a function of rotor angular position relative to the opening of each passage. One cycle (360 degrees) is of duration $0.0285 \mathrm{~s}$ at $2100 \mathrm{rpm}$. Plotted over 5 consecutive rotations, the pressure history is observed to be nearly identical in the two passages, except for high-frequency noise content.

In total, nearly a hundred tests were completed, with thirty-four key tests spanning a considerable range of equivalence ratio condition as shown in Fig. 6. The overall equivalence ratio is based on total air flow, including air within the passage region that is un-fueled. The fueled-region equivalence ratio is based on the portion of air flow into which fuel is injected, and thus indicates the fuel concentration anticipated within the fueled portion of charge assuming perfect mixing at the point of fuel injection and no subsequent mixing downstream. It is noted that the torch igniter delivered a transient traversing jet consisting of an inner core of hot combustion product surrounded by layer of cooling air that protected the torch. The equivalence ratio local to the ignition site is not referred to here. There is some evidence to indicate that the ignition region may have lower equivalence ratio than indicated by inlet air and fuel flow rates, even prior to torch jet injection. Gas samples were taken at the exhaust seal plate to examine the local equivalence ratio prior to the torch ignition. These analyses, although subject to some uncertainty, showed consistently low equivalence ratio (between 0.4 to 0.6 ) rather than the inflow fueled-region equivalence ratio of 1.26 to 1.47. A possible explanation is dilution by air in-leakage near the clearance gap, during a phase of the operating cycle where local passage pressure is sub-atmospheric. 


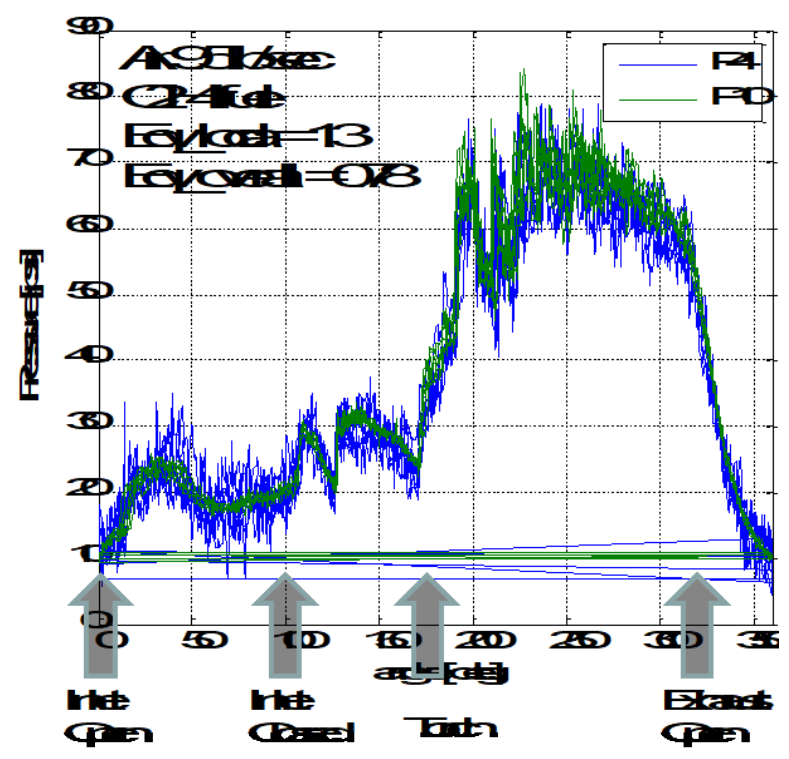

Figure 5. On-rotor pressure traces for 5 consecutive cycles, unfiltered. P4, P10 locations are identical but on different passages.

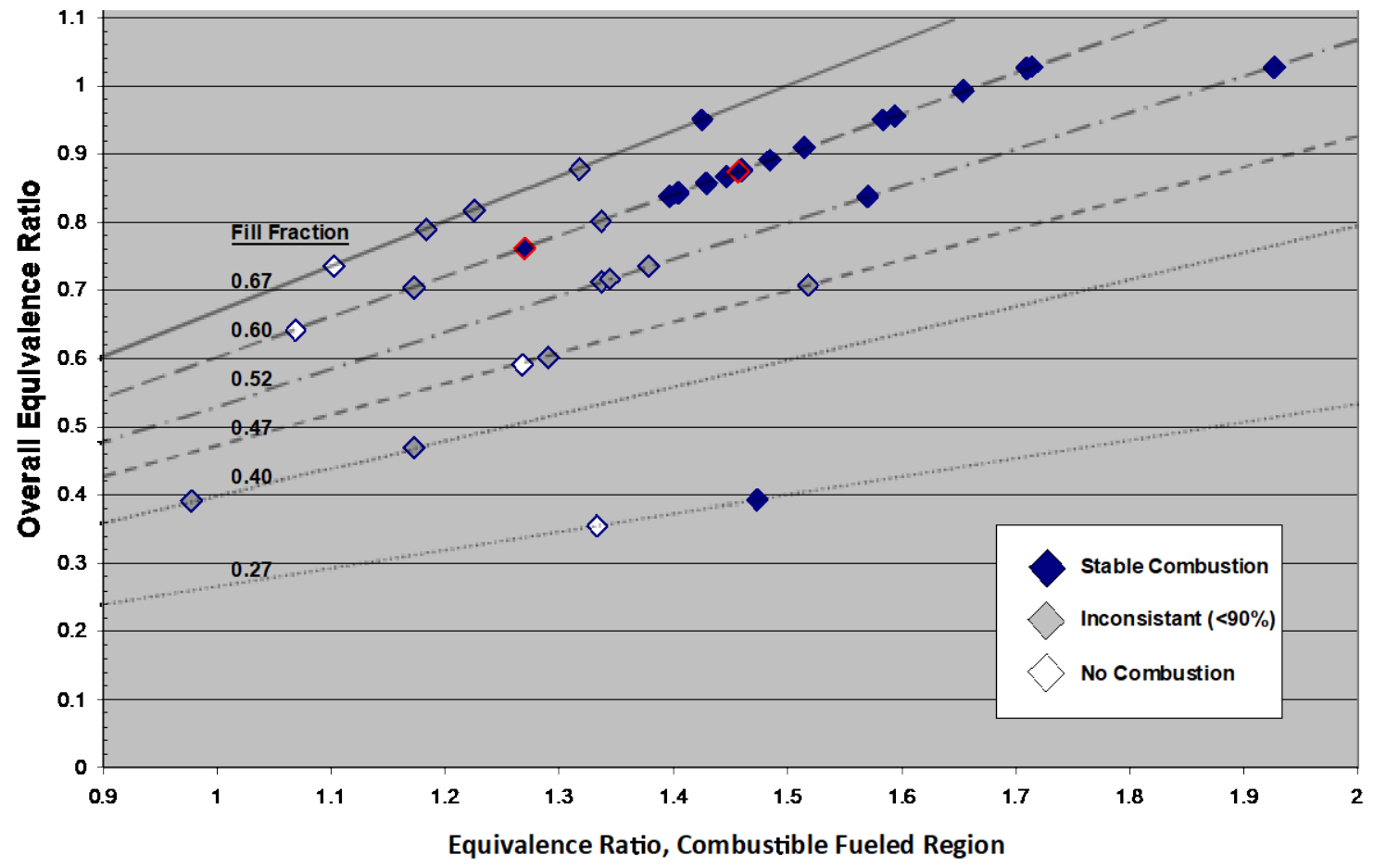

Figure 6 Mapping of WRCVC rig operating regions, indicating observation of combustion and whether consistent. 


\section{Transient Gasdynamics and Combustion Model}

Design of the port locations and predictions of the flow field were made using a time-marching finite-volume model and numerical code, previously validated using pressure-exchange (non-combustion) wave rotor experiments $[15,16,17,5]$. The initial model for design purposes used turbulence and reaction rate parameters based on prior WRCVC literature [7,10-12] and turbulent combustion theory discussed below. The port geometry design [13,14] based on the initial model was found acceptable after these parameters were refined through measurements. The interpretation of measurements presented below will be aided by first examining model predictions and validation. The time-marching, spatially one-dimensional model simulates the transient gas dynamics and combustion in one combustion passage of a WRCVC. Wave rotor operation is dominated by wave and flame propagation along the passages; thus variations in the other directions are considered negligible in the model. The code thus solves onedimensional time-dependent mass, momentum, and energy equations together with equations for species or reaction progress variables, assuming uniform cross-section area and a calorically and thermally perfect gas with constant specific heat ratio $(\gamma)$.

In Eqs. 1-3, vector $\boldsymbol{w}$ represents the conserved parameters while vector $\boldsymbol{f}$ represents the flux and $\boldsymbol{S}$ represents source terms, all in dimensionless form using a selected reference state.

$$
\begin{aligned}
& \frac{\partial w}{\partial t}+\frac{\partial f(w)}{\partial x}=S(w, x) \\
& w=\left[\begin{array}{c}
\rho \\
\rho u \\
\frac{p}{\gamma(\gamma-1)}+\frac{\rho u^{2}}{2}+\sum_{j=1}^{n} \rho z_{j} q_{j} \\
\rho z_{j}
\end{array}\right] \\
& f=\left[\begin{array}{c}
\rho u \\
\frac{p}{\gamma}+\frac{\rho u^{2}}{2} \\
u\left(\frac{p}{(\gamma-1)}+\frac{\rho u^{2}}{2}+\sum_{j=1}^{n} \rho z_{j} q_{j}\right) \\
\rho u z_{j}
\end{array}\right]
\end{aligned}
$$

The source term applicable to the internal region includes the effects of friction, heat transfer, turbulence and species conversion (combustion), and is given in Eq. 4. Leakage-related terms (radial and circumferential) were applied to the passage ends (terminal cells), but their complex details are omitted here for brevity and may be seen together with complete derivation in Ref. 18. 


$$
S_{\text {int }}=\left[\begin{array}{c}
0 \\
\frac{\varepsilon_{t}}{\operatorname{Re}} \frac{\partial^{2} u}{\partial x^{2}}+\sigma_{2} u|\rho u|^{0.75} \\
\frac{\partial^{2}}{2}\left(\frac{u^{2}}{2}+\frac{T}{(\gamma-1) P r_{t}}+\sum_{j=1}^{n} \frac{z_{j} q_{j}}{S c_{t}}\right)+\sigma_{3} u|\rho u|^{0.75}\left(T-T_{w}\right) \\
\frac{\varepsilon_{t}}{\operatorname{Re} S c_{t}} \frac{\partial^{2} z_{j}}{\partial x^{2}}+\sum_{i=1}^{m} c_{i j} R_{i} \quad(j=1, n-1)
\end{array}\right]
$$

Sub-models of loss mechanisms include friction, heat transfer, clearance gap leakage flow, partial (gradual) passage opening/closing, turbulent-diffusion, mixing in the ports, and flow incidence. The friction loss model accounts for the wall shear stress, and wall heat transfer is calculated using Reynolds-Colburn analogy [17]. The walls are assumed to remain at room temperature during the short test duration. Turbulence intensity, which drives axial diffusion [11], is calibrated for observed combustion rate. The value of eddy-diffusivity ratio (turbulent to molecular) is set to 2500, and a turbulent combustion rate coefficient of 0.35 times the eddy-rotation rate. The flow through the clearance gaps between the rotor and the seal plates are modeled as a flow through an orifice [16], including flow through the clearance gap in the circumferential direction from one passage to another [18]. The model was calibrated with the experimental data of the test rig during cold runs, with air flow but no combustion. A coefficient of discharge of 0.8 gave the best match with data and was used for all the simulations presented in this work.

The combustion process is represented by simple one-step or two-step reaction. Modeling of both deflagration and detonation is facilitated in the code, with a specified eddy diffusivity driving turbulent deflagration $[11,12,18]$. The details of the two-step reaction model used here are presented in Ref.18. The combustion model is temperature based, where the reaction is activated when the local temperature of a cell reaches a threshold value equivalent to the ignition temperature $[11,12,18]$. In prior work, a single-step reaction model was used to achieve reasonably good comparison with the experimental data [21,22]. Subsequently, a two-step reaction model with four species was used to better represent stratified mixture combustion, with robust and efficient computation $[18,23]$. In the two-step reaction model, a generic fuel species first undergoes a partial oxidation with oxidant species (air) to form the intermediate products of Eq. 5. If sufficient air is available, the intermediate product is oxidized with additional air to form the final combustion products as shown in Eq. 6. 


$$
\begin{gathered}
\mathrm{C}_{\mathrm{x}} \mathrm{H}_{\mathrm{y}}+\left(\frac{\mathrm{x}}{2}+\frac{\mathrm{y}}{4}\right)\left(\mathrm{O}_{2}+3.76 \mathrm{~N}_{2}\right) \rightarrow \mathrm{xCO}+\frac{\mathrm{y}}{2} \mathrm{H}_{2} \mathrm{O}+3.76\left(\frac{\mathrm{x}}{2}+\frac{\mathrm{y}}{4}\right) \mathrm{N}_{2} \\
\mathrm{xCO}+\frac{\mathrm{y}}{2} \mathrm{H}_{2} \mathrm{O}+3.76\left(\frac{\mathrm{x}}{2}+\frac{\mathrm{y}}{4}\right) \mathrm{N}_{2}+\frac{\mathrm{x}}{2}\left(\mathrm{O}_{2}+3.76 \mathrm{~N}_{2}\right) \rightarrow \mathrm{xCO}_{2}+\frac{\mathrm{y}}{2} \mathrm{H}_{2} \mathrm{O}+3.76\left(\mathrm{x}+\frac{\mathrm{y}}{4}\right) \mathrm{N}_{2}
\end{gathered}
$$

Three independent species variables are defined to model the two-step reaction model, corresponding to mass fractions of fuel, oxidant (air), intermediates (right side of Eq. 5), with final products (right side of Eq. 6) calculated from mass balance. The combustion model follows the eddy-dissipation model [29-33], with the time mean rate of combustion controlled by a turbulent diffusion model [11]. The reaction rate is inversely proportional to the eddy rotation frequency based on Magnussen and Ertesvåg cascade model [31]. Each reaction step is also controlled by the availability of its reactants and products, with each rate is limited by the least available reactant (on a stoichiometric basis), as well as the availability of some reaction products (intermediate or final) that are transported by turbulent diffusion to propagate a reaction front. Details of the two-step combustion model are given by Elharis [18] and Elharis et al [23], including discussion of how eddy diffusivity and the corresponding reaction rate coefficient based on turbulence time scale are estimated by matching experimental combustion data, as turbulence levels inside the passages are not known directly. The flame brush width is estimated to be proportional to the turbulence length scale, which is fixed by the passage hydraulic diameter. For typical conditions, the turbulent flame brush width is estimated to be $7.5 \mathrm{~mm}$. Therefore, 500-1000 computational cells is considered the minimum mesh size. In the calibrated model, the local turbulent flame propagation speed is estimated to be about $80 \mathrm{~m} / \mathrm{s}$ [18]. While this appears much higher than what is typical in piston internal-combustion engines, it is noted that the onedimensional equivalent speed must be carefully interpreted, as the flame may have significant three-dimensional non-planar features. Furthermore, flame propagation is expected to be strongly affected by baroclinic vorticity production [34-37] through interaction with shocks and pressure waves, as well as the increase in chemical kinetic rates with rapid internal pressurization.

Ignition is achieved using hot gas jet injected from the torch igniter. The hot gas jet mixes with the air-fuel mixture, forming multiple vortex structures as observed in multi-dimensional fluid flow simulations and experiments with a traversing hot jet ignition [38-42]. Within the vortices, ignition is predicted to occur where and when hot combustible charge develops. For the purpose of the simpler one-dimensional model, the apparent ignition locations and timing have been estimated from experimental data using pressure transducers and ion probes [18,25]. 
Typically, two apparent ignition locations are used: one at exhaust wall side, where the torch igniter is installed, and one at some stand-off distance corresponding to the vortex structures, with calibration of location and timings.

Roe's flux-splitting method is applied to solve the approximate Riemann problem. The model is integrated using Lax-Wendroff's second-order scheme. The details of the method of integration and the boundary conditions treatment are comprehensively discussed by Paxson [15]. The solution grid independence was examined using different spatial meshes, with time step matched to maintain the same Courant number and ensure numerical stability $[23,18]$. The simulation with 800 cells was deemed to present a grid-independent solution. This mesh size is consistent with the grid-density requirements based on the turbulence properties and flame structure discussed in Ref.18. Three parameters were adjusted to provide the best possible agreement with the test data: combustion ignition location, heat release, and reaction rate, but were held constant when considering multiple cases. The detailed structure of the wave process are replicated well at multiple sensor locations, as discussed in the next section.

\section{Numerical Model Validation}

The numerical model validation is illustrated with two test runs of the rig (Table 1) in which on-rotor combustion was successfully achieved, with different fuel distribution in the passage. The operation of WRCVC test rig and the dynamics of its operation are discussed in more detail in prior publications $[18,20,27,24]$. In each case the fuel introduction system was set to provide fuel via nine of the fifteen available fuel injection positions depicted in Figure 4 and Figure 3, upper.

Table 1. Operating conditions for test cases

\begin{tabular}{llll} 
Parameter & Unit & Case A & Case B \\
\hline Air flow rate & $\mathrm{lb} / \mathrm{s}$ & 9.41 & 9.41 \\
Fuel flow rate & $\mathrm{lb} / \mathrm{s}$ & 0.56 & 0.56 \\
Torch flow rate & $\mathrm{lb} / \mathrm{s}$ & 0.17 & 0.17 \\
Intake air pressure & $\mathrm{psia}$ & 20.77 & 20.77 \\
Fuel mix equiv. ratio & - & 1.46 & 1.46 \\
Rotational speed & $\mathrm{rpm}$ & 2100 & 2100 \\
Active fuel injectors & - & $\mathrm{F} 1$ - F9 & F3 - F11
\end{tabular}

The two test cases have the same targeted rotor speed, main air flow rate, ethylene fuel flow rate and torch igniter flow rate, which are all set in the simulation. The port boundary conditions are specified through an iterative 
process to match the flow rates of the simulations with that of the experiments, as there is no direct measure for the pressures and temperatures at the rotor interfaces. The port boundary conditions are summarized in Table 2. This prescribed torch temperature is intended simply to overcome the threshold ignition temperature in the combustion model. Multi-dimensional modeling of torch jet ignition is the focus of work reported in Ref. [42]

Table 2. Port boundary conditions for simulation model

\begin{tabular}{ll} 
Parameter & For Cases A \& B \\
\hline Inlet total pressure & 17.9 psia \\
Inlet total temperature & $520 \mathrm{R}$ \\
Exhaust static pressure & 14.7 psia \\
Torch total pressure & $129.3 \mathrm{psia}$ \\
Torch total temperature & $3120 \mathrm{R}$
\end{tabular}

The simulation results are typically presented as level plots on a developed (unwrapped) view of the passages. The x-axis represents the longitudinal position in the passage normalized with the passage length (reference to zero at the inlet wall). The y-axis represents the angular position of the passage in degrees (reference to zero when passage center aligns with inlet port leading edge). The level plots are presented for the species mass fractions, dimensionless temperature and natural log of dimensionless pressure. The seal plates are represented with two black lines at the edges, and the white spacing indicates the inlet port $(\mathrm{x} / \mathrm{L}=0.0)$ and exhaust port $(\mathrm{x} / \mathrm{L}=1.0)$. The reference conditions for dimensionless parameters are listed in Table 3.

Table 3. Reference state conditions for dimensionless parameters

\begin{tabular}{ll} 
Reference Parameter & Reference Value \\
\hline Reference Pressure & $14.696 \mathrm{psia}$ \\
Reference Temperature & $520^{\circ} \mathrm{R}$ \\
Reference Density & $0.0763 \mathrm{lb} / \mathrm{ft}^{3}$ \\
Reference Speed of Sound & $1118 \mathrm{ft} / \mathrm{s}$ \\
Specific Heat Ratio & 1.33
\end{tabular}



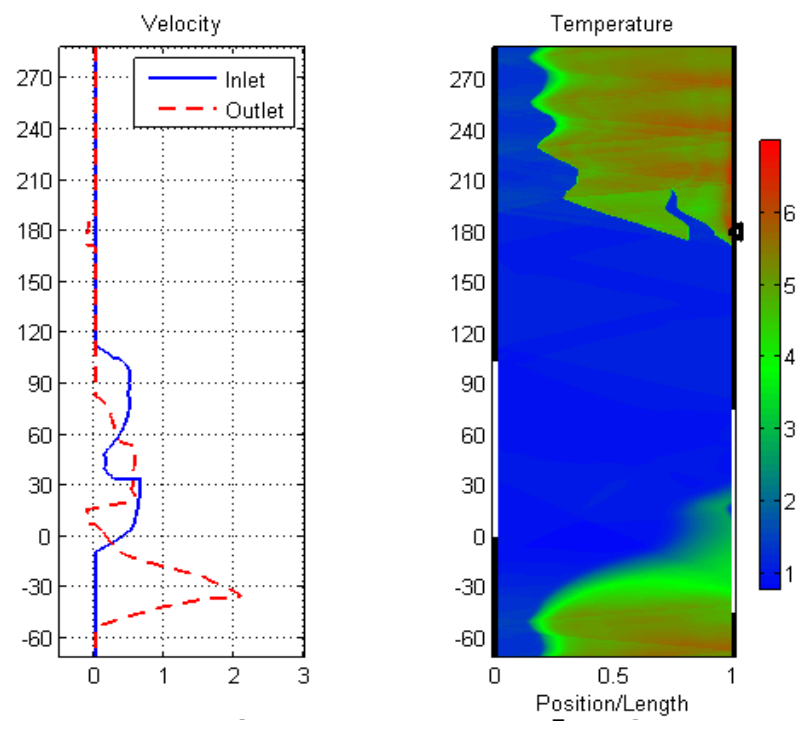

Figure 7. Fuel mass fraction and dimensionless temperature level plots (Case A)

\section{A. Case A}

Fuel is injected through injectors F1-F9 in the inlet duct, with no fuel in injectors F10-F15. Fuel-air mixing is assumed to occur in the inlet port and corresponding concentration boundary conditions are applied at the inlet. Ignition was posited to occur at two locations $\mathrm{x} / \mathrm{L}=0.8$ and 1.0 when the passage is at angular position of $175^{\circ}$ (i.e., $7^{\circ}$ after the passage opens to the torch igniter). This ignition model was based on detailed evaluation of test data and multi-dimensional modeling of the traversing jet ignition process in multiple vortex structures $[18,25]$. Consumption of fuel mixture and production of hot burned gas, and their axial movement, are shown in level plots of fuel mass fraction and dimensionless temperature (Fig. 7). Since the air-fuel mixture is mainly rich in this case, the available oxidant allows formation of intermediate species rather than complete combustion products. It is noted that some of the fuel is predicted to be spilled out through the exhaust port. This spillage is estimated by simulation to be $8 \%$ of the total fuel supplied.

The predicted propagation of flame fronts is compared with signals from ion probes (yellow bars) overlaid on intermediate species mass fraction in Fig. 8. It is encouraging that the ion signals appear immediately after the predicted appearance of intermediate species and appear to support the two-point ignition model. Isobaric contour lines (black) represent pressure waves that drive a sloshing motion of the gas and flame fronts, resulting in consistent multiple signals captured by probe I8. 


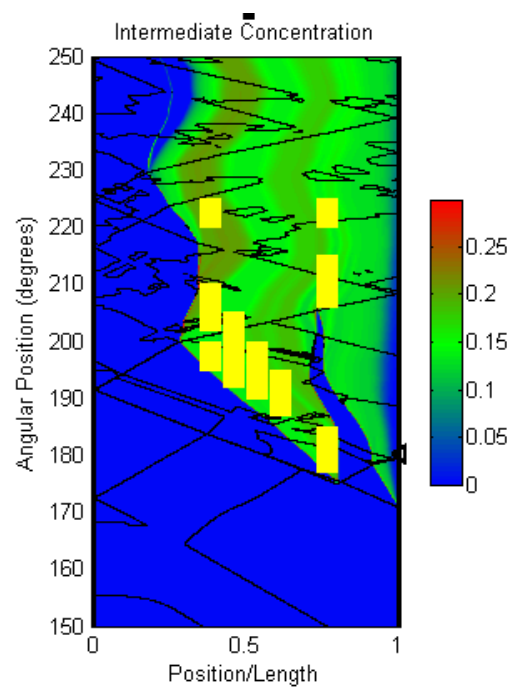

Figure 8. Flame ion measured (yellow) compared with intermediate production (Case A)

Shown in Fig. 9 are the variation of pressure, as well as boundary velocity profiles. These are supported by measurements discussed below. The velocity profile at the exhaust duct indicates a slight backflow at angular position $\sim 10^{\circ}$ due to the reflection of the expansion fan from the exhaust port as a compression wave, which later (at $\sim 35^{\circ}$ ) causes a reduction in inlet velocity (Fig. 9, left). Ambient pressure and temperature were applied as boundary stagnation properties during this minor backflow period.
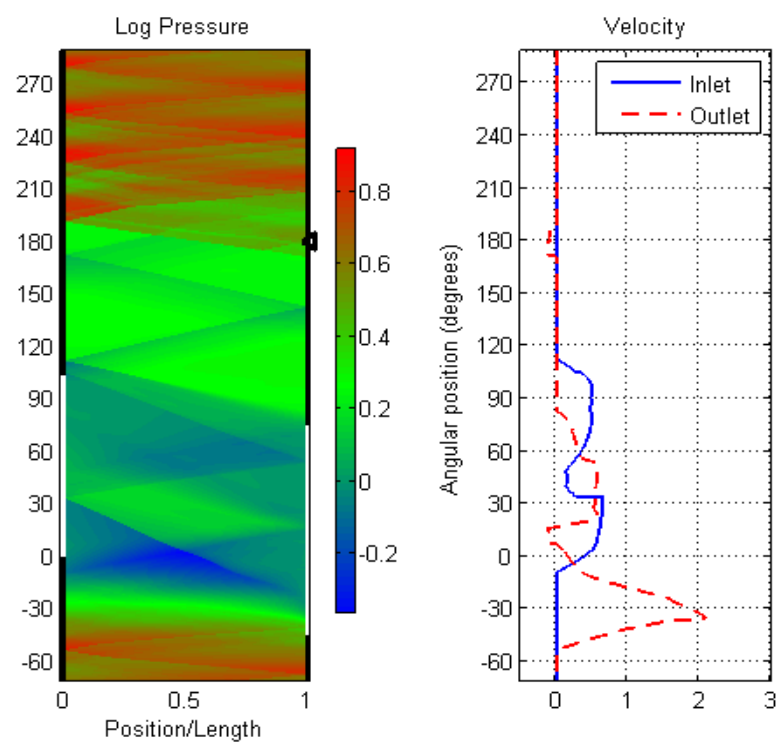

Figure 9. Dimensionless pressure level and boundary velocity profiles (Case A) 
Predicted pressure traces for P2 and P5 are overlaid on transducer signals in Fig. 10. Angular position from $0^{\circ}$ to $360^{\circ}$ is recorded by a shaft encoder. Remarkably consistent with measurements, the model predicts different pressure patterns for the two transducers, mainly because P5 is closer to the acoustic sources and refracting density interfaces caused by combustion. The fidelity of the calibrated model allows understanding of the complex transient gas dynamic and turbulent combustion phenomena beyond the limitations of instrumentation. However, for both transducers, the initial pressure rise due to ignition in Case A appears to occur slightly earlier and more gradually than predicted. This may be related to hot gas transfer via a known end wall space around the igniter, which may advance ignition at the near-wall location, but not at the stand-off location. As seen below, this discrepancy is not observed when fuel spillage at the exhaust end is avoided in Case B. Fuel proximity effects are examined in Ref. 25 using multi-dimensional modeling. 

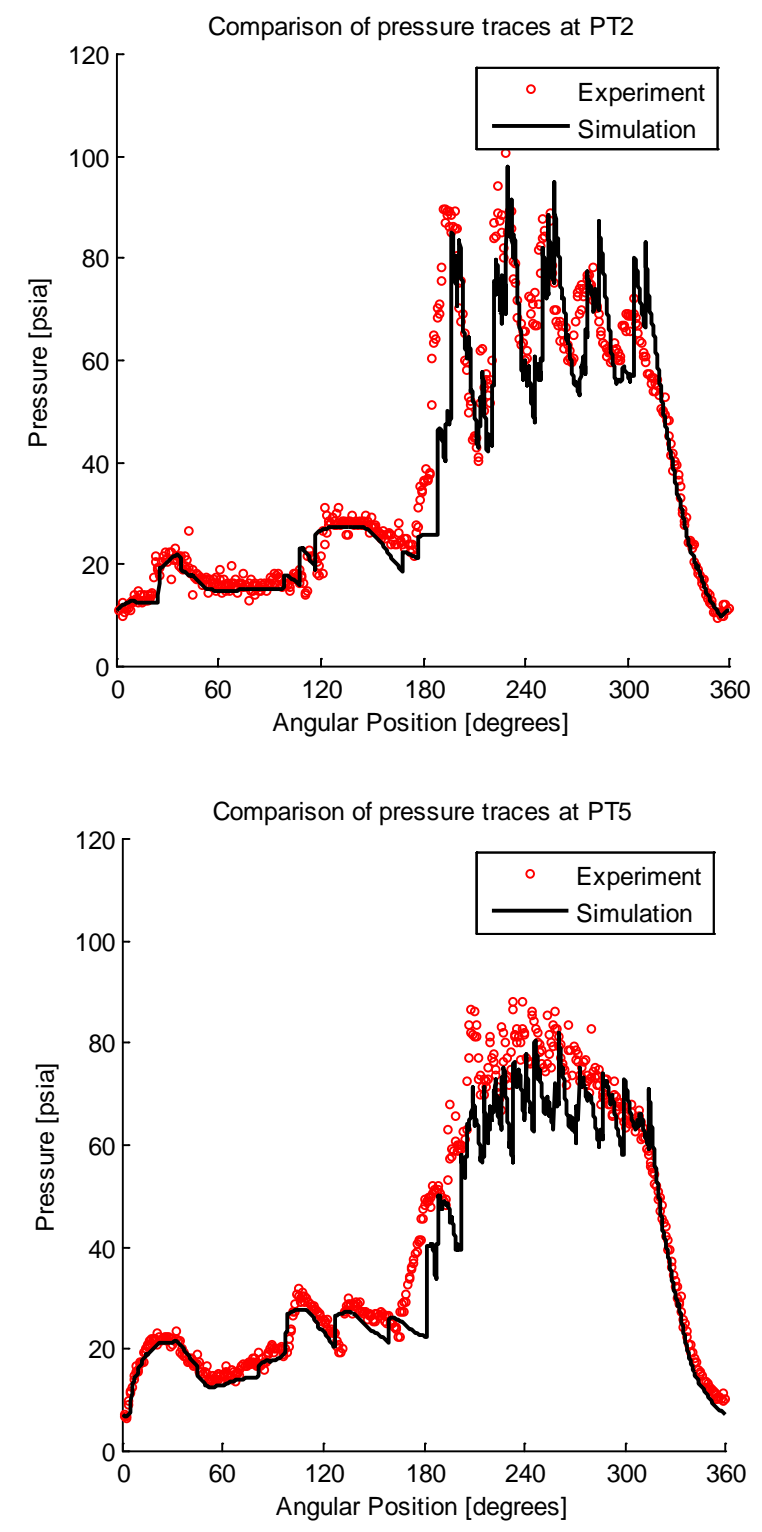

Figure 10. Pressure traces comparison (Case A)

\section{B. Case B}

In Case B, fuel distribution was modified to avoid fuel spillage at the exhaust prior to combustion. Nine injectors, F3-F11, were supplied with fuel, providing fuel/air mixture to the corresponding portions of the inlet, while injectors F1-F2 and F12-F15 had no fuel supply. Boundary conditions remain the same as indicated in Table 2, except for inlet fuel species concentration. Predicted fuel mass fraction and temperature histories for this configuration are presented in Figs. 11, confirming that no fuel spillage occurred based on examining the 
distribution of fuel at the end of the filling process. The boundary velocity profiles (Fig. 12) indicate higher peak velocities, which is due to the stronger waves generated by higher peak combustion pressure resulting from a greater amount of fuel burned. By comparing pressure peaks for Cases A and B, the effect of $8 \%$ fuel spillage in Case A resulted in $\sim 25 \%$ reduction in pressure rise inside the passage, with $\sim 12 \%$ reduction in the predicted overall pressure gain.
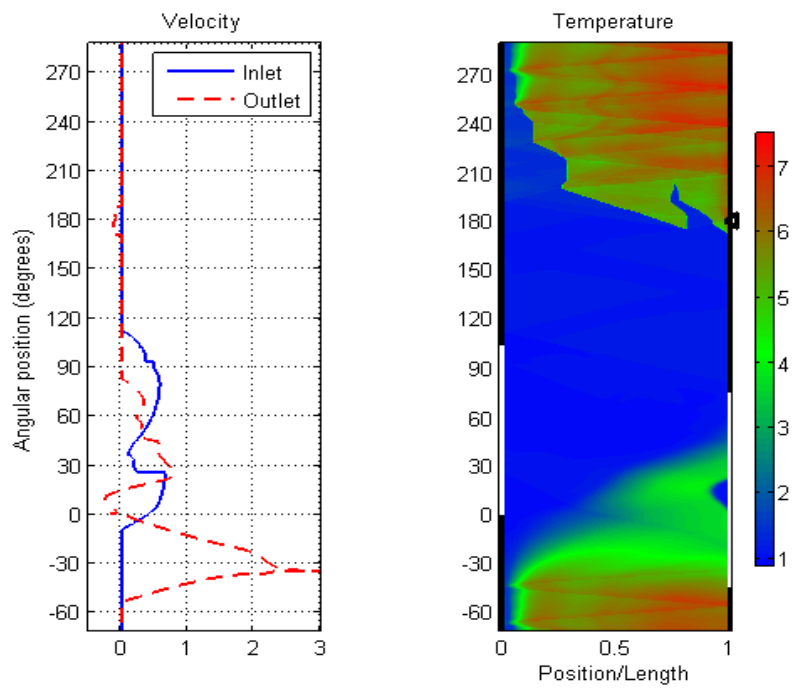

Figure 11. Fuel mass fraction and dimensionless temperature level plots (Case B)
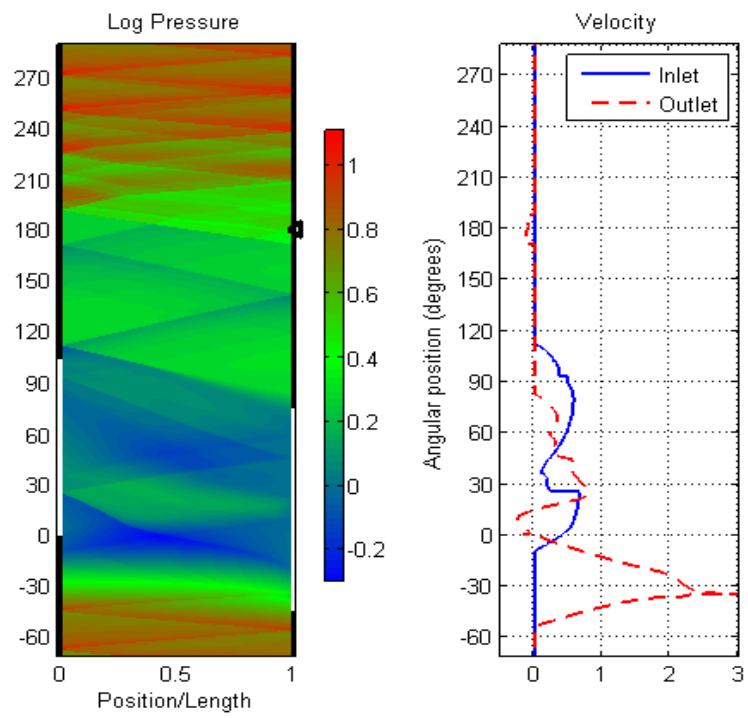

Figure12. Dimensionless pressure level plot and boundary velocity profile (Case B) 


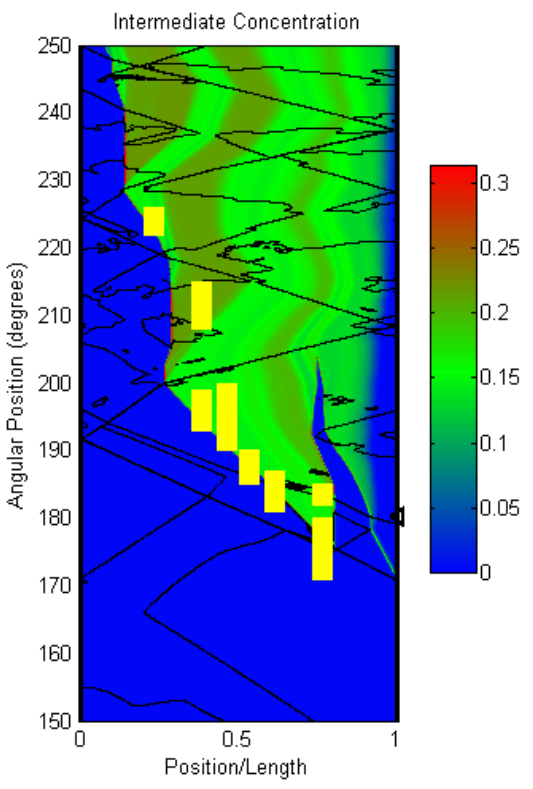

Figure 13. Flame ion measured (yellow) compared with intermediate production (Case B)

Experimental data for flame propagation (ion probe signal) is compared with the predicted flame propagation as presented in Fig. 13. The flame ions appear with the expected apparent flame speed but slightly earlier than predicted by the simulation, and with some differences near the ignition source that may be related to residual air near the right end wall. Predicted pressure traces from P2 and P5 are overlaid on measured signals in Fig. 14, with the different patterns at the two location showing remarkably consistent match of the timing of pressure peaks and troughs and the overall pressure amplitude. The start of combustion pressure rise appears to be better predicted than for Case A, possibly because the lack of fuel adjacent to the end wall prevents ignition until the torch jet penetrates into the fueled region. 

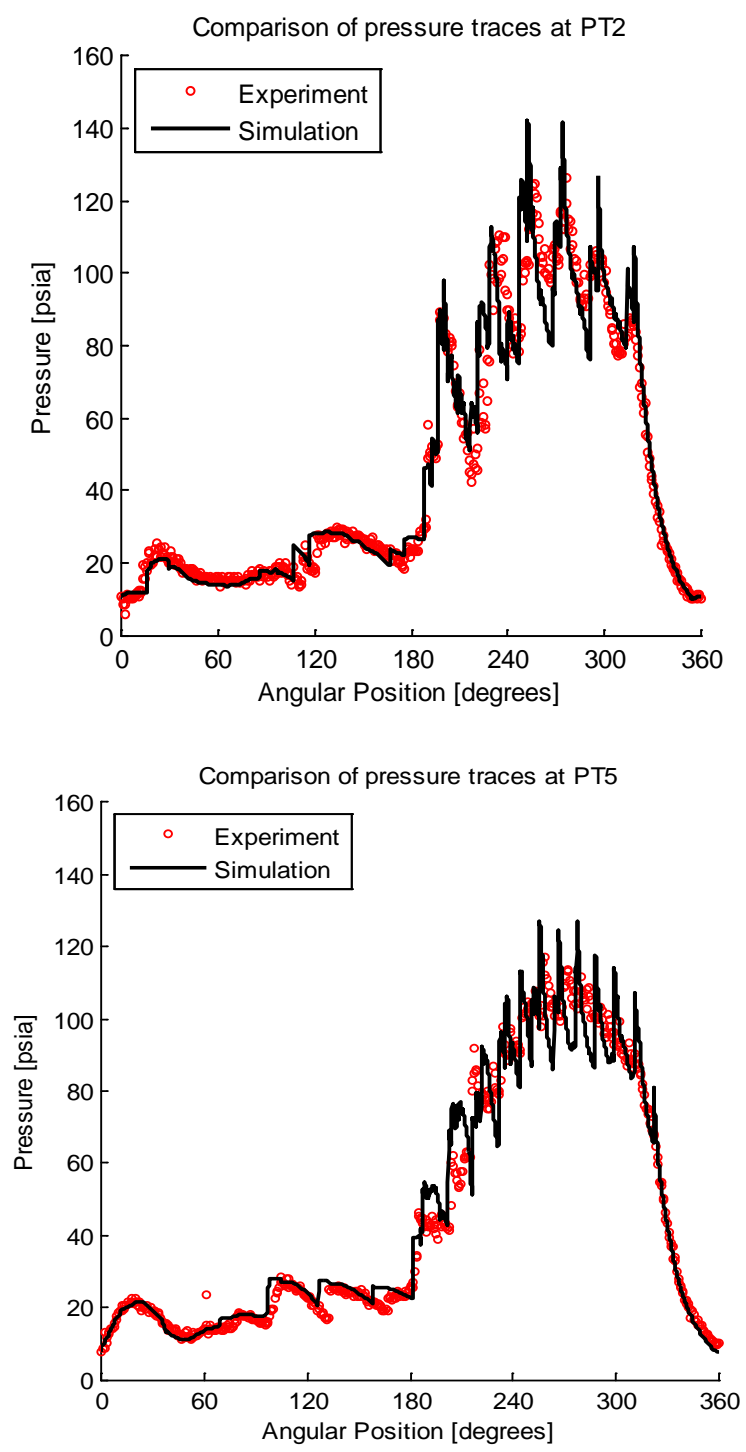

Figure 14. Pressure traces comparison (Case B)

In summary, we see that for both Case A and Case B, experimental pressure and ionization data comparison with the simulations validate the model used to design the WRCVC and predict its cyclic operation. It should be noted that pressure sensors are not expected to respond to the full predicted amplitude of a shock wave, due to diminished sensor response at the high frequencies. The P5 sensor, which is in the very hot region, appears also subject to more noise, due to sensor temperature effects. Thermocouple measurements are presented separately below. 


\section{Examination of Flame Ion Signals to Evaluate Cycle-to-Cycle Variability}

This section and the next two present measurements from a typical test run, Case C, that is more fully documented in Ref. 20. This test run is substantially similar to the run and simulation presented as Case A above as well as a test run discussed in Ref. 21 as “Case B” with a simpler numerical model. The rotor was spun to 2,100 rpm rotor speed and the air flow rate set at $9.6 \mathrm{lbm} / \mathrm{sec}$, with inlet total pressure at 21.7 psi during the main combustion duration. Ethylene fuel flow of $0.51 \mathrm{lbm} / \mathrm{sec}$ via Injectors F1-F9 was turned on for $1 \mathrm{~s}$ duration. The equivalence ratio in the combustible fueled region is estimated at 1.31.
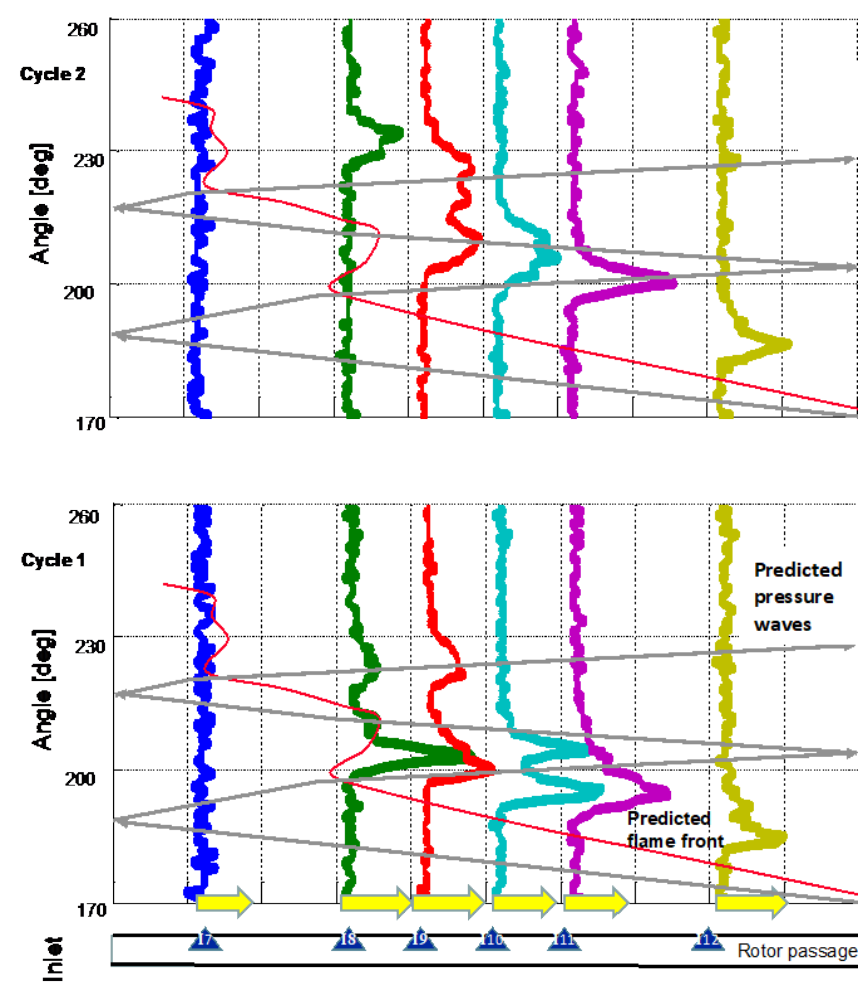

Figure 15. On-rotor ion probe (I7-I12) signals for consecutive cycles overlaid on predicted waves and flame front, Case C [20].

While a repeatable combustion pressure trace is established within a fraction of a second of main fuel activation, deeper examination of flame propagation does reveal significant cycle-to-cycle variability, much as expected in any intermittent combustion device. The ion probe requires direct contact with an active combustion process, but the sensor only protrudes $1 / 4$ inch into the passage. Ion probe signal traces are presented for two consecutive cycles in Fig. 15, at multiple locations. Each signal (thick colored traces) is positioned along the horizontal axis proportional 
to probe position, with equal horizontal scales. In some cases, multiple peaks were recorded at one location as the gas 'sloshes' the flame in the chamber. The gas motion and flame front location (thin red wavy line) were predicted by a simpler version of the simulation model. The predicted compression wave trajectories (thin grey lines) reveal motion of the gas that embeds the flame. It is noted that the measured flame trajectory is not as repeatable as the measured pressure trace data shown previously. This may be attributable to the highly multidimensional nature of the flame front, so that the ion probe on one side wall may be touched by the flame at slightly earlier or later times, whereas the overall heat release driving pressure history may not vary much. At filling, there is no fuel delivered to the left half of the passage; the appearance of flame in the left half (nearly to the position of probe I7), is due to expansion of hot gas from combustion in the right half. Relative to the wall, the flame appears to travel at over half of the sonic speed, but remains a fast but subsonic deflagration relative to the unburned gas.

\section{Rotor and End Wall Temperature Measurements}

On-rotor temperature for Case C was recorded by K-type thermocouples located per Fig. 4, intruding about 0.125 in into the combustion chamber. Much slower than pressure and ion sensors, thermocouples respond to rotor gas temperatures (Fig. 16) over multiple operating cycles (each 0.0285 s). The recorded temperature at each location may roughly be considered as averaged over each cycle, but not a simple time-average. The operating conditions were as given in the last section. The igniter is turned on prior to this recording, causing slight initial heating at T8T10. The fuel valve was turned on for one second at the $214 \mathrm{~s}$ mark, followed by ignition after a fractional second for travel, as indicated by the start of temperature significant rise. After fuel cuts out at $215 \mathrm{~s}$, the temperatures rise as combustion continues until fuel-free air fills the rotor. Sensor T10 reached nearly $1500^{\circ} \mathrm{F}$ for longer firing (3 s)

under similar conditions. According to the corresponding simulations, the contact surface for pure air and reactant mixture lies at about the mid point of the passage, near T4 prior to combustion. During combustion the contact surface location moved as near as 4 in distance from inlet, and oscillated near the I7 and T2 location, Fig. 4. 


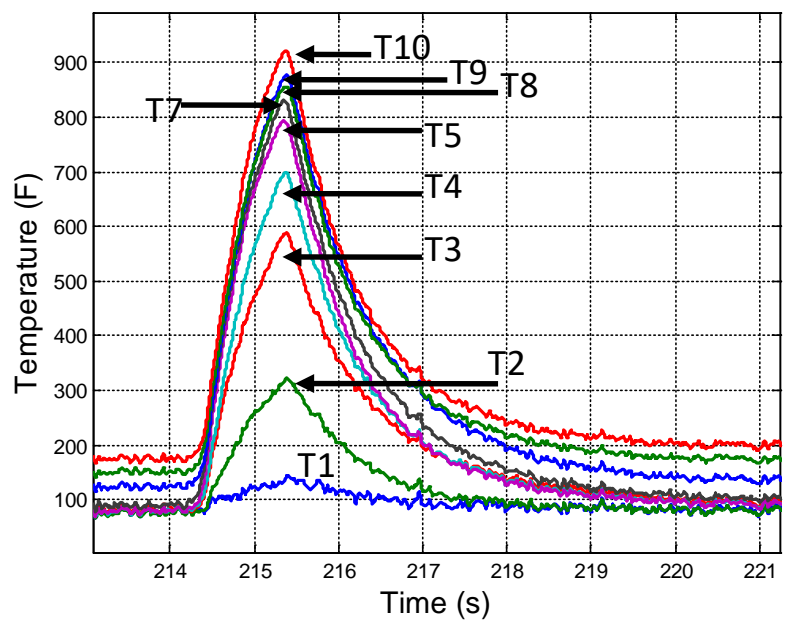

Figure 16. On-rotor temperature measurement over run time period, Case C [20]

The seal-plate end-wall thermocouples are continuously exposed to hot or cold gas during firing operation (Fig. 17). The exhaust-side T23-T26 sensors, located immediately following the igniter, recorded the highest temperatures, depending on the test conditions, and also show heat from the igniter prior to main fuel activation. For longest duration ( $3 \mathrm{~s}$ ) firing, the highest temperature of approximately $2000^{\circ} \mathrm{F}$ was measured at $\mathrm{T} 24$ and $\mathrm{T} 25$. Interestingly, T22 indicates propagation of combustion flame and/or torch igniter exhaust immediately ahead of or prior to arrival of a passage at the igniter, while T19-T21, located further upstream, showed no heating. Computational modeling for this operating condition predicted that hot combustion products were completely exhausted every cycle, with inflow spillage of approximately 7.1\%.

Relatively small temperature changes were recorded at the inlet seal plate, which is not contacted by hot combustion gas. This mostly reflects temperature rise due to compression, which occurs by wave action before fuel combustion, and mainly combustion pressure rise after fuel introduction. Compared to the close measurement among T14, T15 and T16, the temperature measured at T17 and T18 were clearly lower than these three. This observation and the more subtle variations of these temperatures require more investigation. 

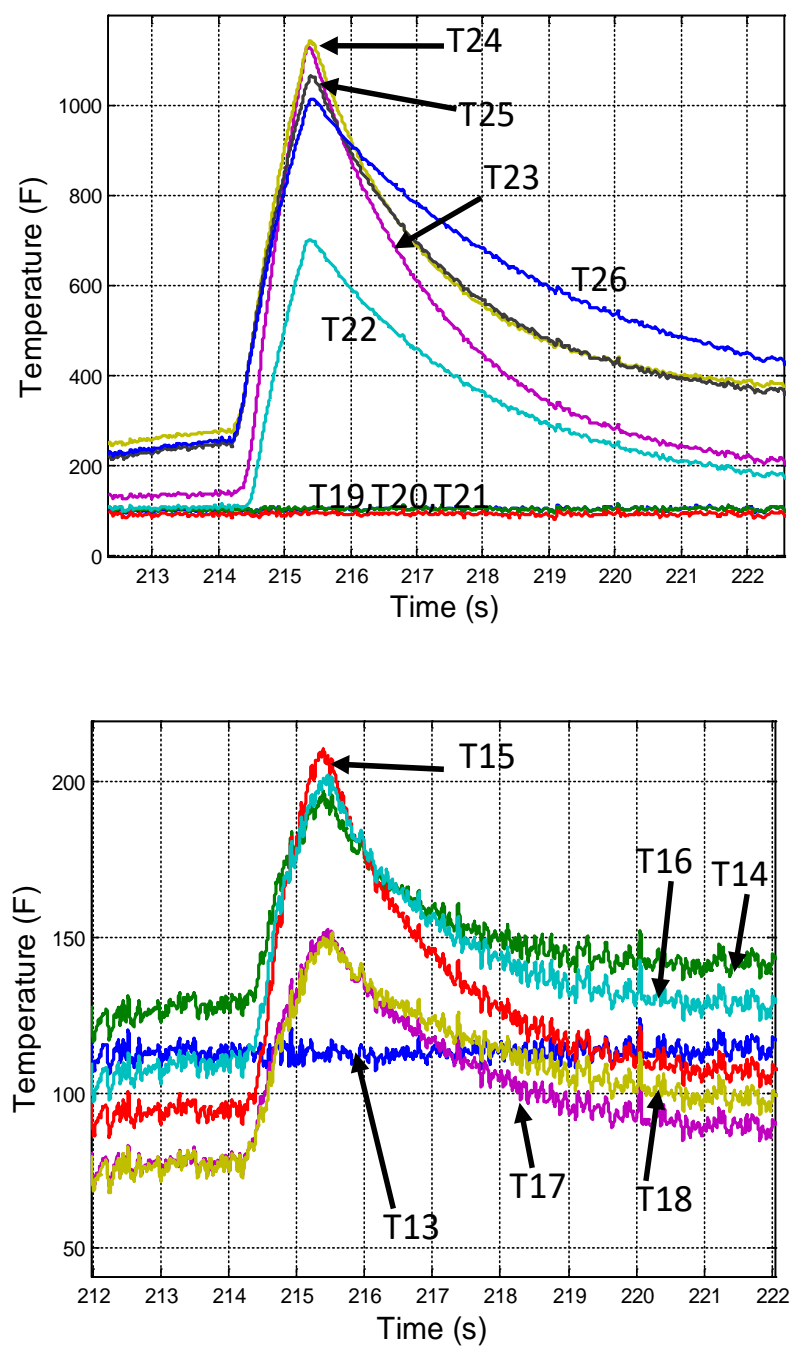

Figure 17. Exhaust (upper) and inlet (lower) seal plates temperature measurement, Case C [20]

\section{Inlet/Exhaust Measurements}

The inlet total pressure measurement for Case C is presented in Fig. 18. It should be remembered that a choked upstream orifice in the facility air supply system is designed to maintain a fixed inlet air mass flow, and the outflow static pressure is held constant (atmospheric discharge). The nominal inlet total pressure was about 22.25 psi prior to torch ignition. As the torch igniter was fired, inlet total pressure dropped by approximately 0.25 psi. Combustion started when the fuel flow was initiated at 214 seconds, and the inlet pressure dropped further by approximately 0.5 psi. These drops in inlet pressure are expected due to torch and main combustion as pressure increase in the passage causes stronger wave action and suction at the inlet. However, the main combustion-driven inlet depression is 
moderated by fuel flow, which should be carefully considered. The effect of the fuel flow alone can be observed at around 198 seconds in the plot. Following a purge with nitrogen to release any unwanted gas accumulation in the fuel plumbing, the fuel flow was activated without ignition to prime the lines. During this period, the inlet total pressure increased approximately 1.0 psi from the nominal pressure, due to fuel injection into cross flow at approximately the same rate as during the combustion test. The inlet system should experience a similar pressure rise during the combustion process due to the fuel addition. If the effect of fuel addition is considered, the inlet pressure decrease during combustion could be approximately 1.5 psi compared to pre-combustion torch igniter operation. It is anticipated that the pressure drop due to fuel addition in a high-speed cross flow would be significantly reduced in more optimal design of fuel-air mixing in a practical application.

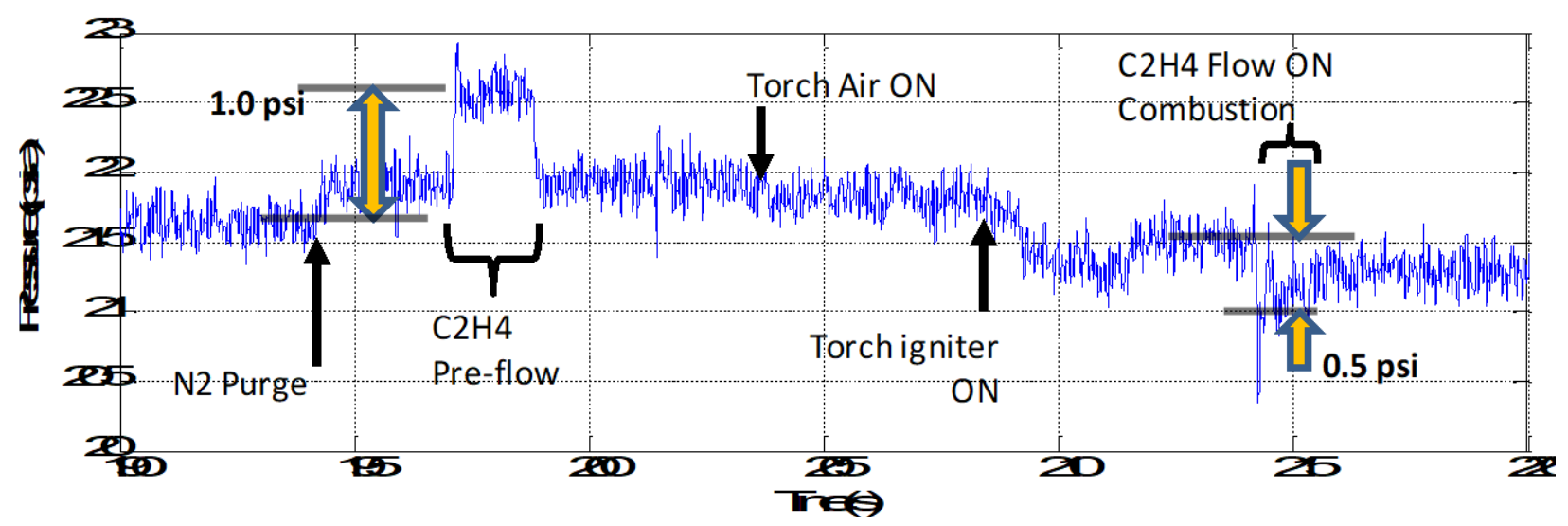

Figure 18 Inlet total pressure measurement [20], Case C

In a subsequent set of tests [27], an exit total pressure rake was installed, having 6 elements placed on centers of equal areas at the exhaust discharge plane (Fig 3b) and connected to a mid-range data sampling rate system. One test run is reported here with a main air flow rate of $9.3 \mathrm{lb} / \mathrm{s}$ with an inlet pressure of $20.5 \mathrm{psia}$, and fuel flow rate of 0.56 $\mathrm{lb} / \mathrm{s}$ for an overall equivalence ration of 0.88 during the firing period. The rotor speed was $2100 \mathrm{rpm}$. Exhaust duct measurements in this test run (Fig. 19) show that significantly increased total pressure readings were recorded over the portion of the duct near the position of rotor passage opening and initial discharge. The exhaust total pressure probe measurements match well with model prediction when the pressure data predicted in the passage frame-ofreference is converted to that for the probe. It is noted that some pressure losses may be incurred as the flow is forced to follow the path of the duct. It is envisioned that the duct angle can be optimized and additional features can 
be applied in an operational device to create a greater spatial uniformity in the discharge pressure. Rig instrumentation did not include exhaust gas temperature measurement.

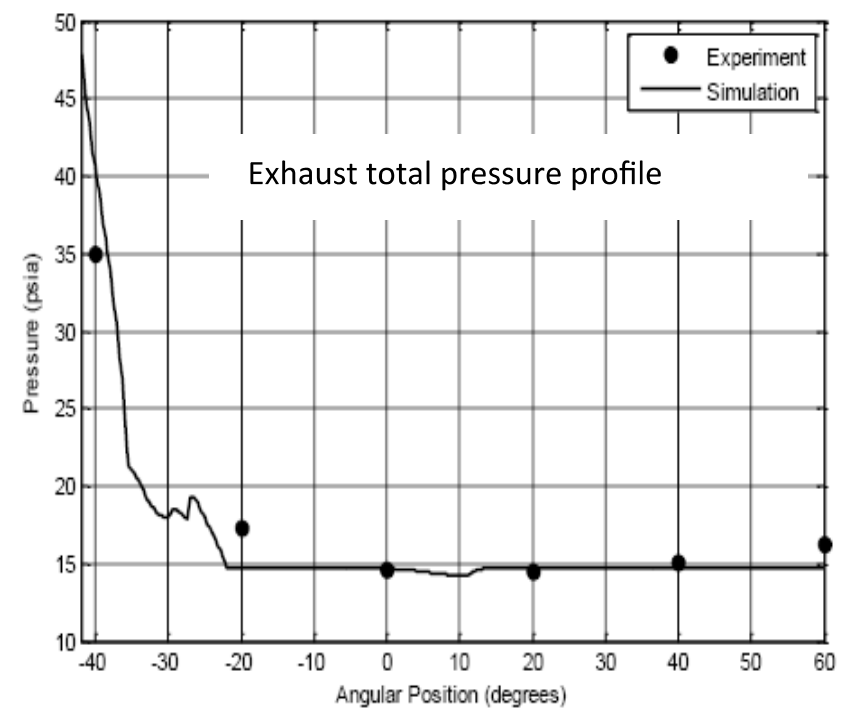

Figure 19. Total pressure in the exhaust during firing, [18] compared to prediction

\section{Inferences Regarding Pressure Gain and Pressure Fluctuation}

It is reiterated that the WRCVC rig was not designed to demonstrate a pressure gain, but rather was designed to determine the characteristics of the on-rotor combustion process. Significant compromises in the combination of duct placement, rotor speed, fuel injection, and torch igniter placement were made that reduce the pressure gain potential but allowed the rig to be able to operate regardless of the combustion speed realized. Even so, indicators of performance gain potential are discernable from the data.

An indicator of this potential was the response of the pressure within the inlet upon combustion within the rotor as noted above. A noticeable drop in inlet pressure accompanied the start of combustion. A separate lumped-volume analysis [26] has shown that upstream plenum volumes are small compared to the flow rates, such that dynamic effects within the inlet section are small. The inlet pressure decrease compensates for a pressure rise generated within the WRCVC, so that the same mass flow rate is maintained. This behavior matches prediction and is a clear, though indirect, evidence of achieving pressure gain from combustion.

Based on the heat release estimated from the simulation, considering oxygen-limited partial combustion in rich zones, the predicted overall temperature ratio for this test is 3.97. For this temperature ratio, the calibrated model 
provides an estimate of overall pressure gain as 38\%, based on constant-area mixing in the exit port that conserves mass, momentum, and energy. It is noted that this is not equivalent to simple arithmetic averaging or weighted averaging of total pressure profiles such as that presented in Fig. 19. In most gas turbine applications, the temperature across the combustor would be limited a lower value. An additional test case was run with a predicted operating point temperature ratio of 2.63. The model's estimate for pressure gain in this case is $19 \%$.

During the combustion phase of the cycle when both ends of the passage are closed, the unfiltered pulsating component of exhaust pressure was approximately $\pm 7 \mathrm{psi}$, whereas the gas pressure within the rotor passages varied $\pm 90 \mathrm{psi}$, both subject to similar instrumentation time response. These are consistent with model predictions. This represents an important aspect of the WRCVC type of pressure gain combustor in that the exhaust pressure variations in time exhibit less than a tenth of the internal pressure transients.

\section{Conclusion}

A wave rotor constant-volume combustor rig was built and operated reliably over a range of test conditions. In addition to demonstrating the viability of the WRCVC approach as a pressure-gain combustor, a significant amount of experimental and modeling data has been generated beyond any prior known work on this concept. Results show the viability of this configuration for forming a pressure-gain combustor and are promising regarding its utility for future turbine engine development. The observed operation of the rig validated the design intent and the accuracy of the modeling approach. The success of the WRCVC test series was reinforced by the demonstration of multiple advantageous characteristics.

Measurements of inlet pressure response to combustion, exhaust total (stagnation) pressure during combustion, and internal cyclic pressure as compared with modeling, individually and together strongly imply that a net pressure gain can be delivered. The rapidity of combustion also supported the viability of the WRCVC approach. The reaction zone indicated by the ion probes showed that very fast deflagrative flame propagation is possible, a characteristic important in creating a compact highly self cooled unit. The apparent axial flame travel rate was as high as $200 \mathrm{~m} / \mathrm{sec}$ or over half of the acoustic velocity, relative to the passage walls, and including gas motion

effects. Relative to unburned gas, it was estimated that the axial propagation speed of the flame averaged about 80 $\mathrm{m} / \mathrm{s}$. While the unburned mixture may be highly turbulent, it is believed that this flame propagation rate is strongly 
influenced by baroclinic vorticity generation through pressure-wave interaction, and may not be compared with typical turbulent flame propagation. The design provided excellent isolation of combustion from premixed filling as indicated by the absence of backfire during the test despite the large clearance gap levels at the rotor ends. The achievement of consistent combustion with non-contact seals at relatively open clearances indicates that sealing is reduced to a performance issue, and not an operability issue. Additionally, backfire was absent during shutdown when employing a proper sequence of fuel flow stopped before torch termination.

Stable operation was indicated to be possible over a broad range of overall equivalence ratios from 0.39 to 1.03 . For all the test conditions conducted, combustion was more successful with relatively higher equivalence ratios in the combustible fueled region. The range for more successful ignition appeared to be in the rich range, but this could not be confirmed by gas sampling due to possible air infiltration and torch igniter cooling flow. Pressure measured in the rotor passages indicated very little cycle-to-cycle variation and almost no passage-to-passage variation. However, the ion probe profile varied somewhat from cycle to cycle, since the sensor is on one wall and thus oblivious to expected three-dimensional variations in the flame structure.

The two-step reaction model with four species variables was found to offer a satisfactory level of detail necessary for modeling combustion of stratified charges in WRCVC with the time-dependent, one-dimensional model. Using consistent model parameters and fixed values of eddy-diffusivity and turbulent combustion rate coefficient as reported, the model simulations matched numerous experimental data sets reasonably well. The model offers reliable predictions for the pressure traces inside the passages and for the flame propagation inside the passages, and can account for flammability limits. The utility of the model to as a design tool for future development is highly encouraging.

\section{Acknowledgments}

Financial support for this work from the $21^{\text {st }}$ Century Fund of the State of Indiana, Rolls-Royce North American Technologies Inc. (LibertyWorks ${ }^{\circledR}$ ), and the participating universities is gratefully acknowledged. The work reported here was carried out by the authors and Yu Matsutomi, Masayoshi Shimo, Scott Meyer, Sameera Wijeyakulasuriya, Tarek Elharis, Zuhair Izzy, Keith Smith, and other supporting personnel at the author’s affiliate institutions. 


\section{References}

1. Azoury, P. H., “An Introduction to the Dynamic Pressure Exchanger,” Proc. Inst. Mech. Eng., 180(18), Part 1, 1965-1966, pp. 451-480.

2. Kentfield, J. A. C., "The Pressure Exchanger, An Introduction Including a Review of the Work of Power Jets (R\&D) Ltd.," Proceedings ONR/NAVAIR Wave Rotor Research and Technology Workshop, Naval Postgraduate School, Monterey, CA, Report NPS-67-85-008, 1985, pp. 9-49.

3. Akbari, P., Nalim, M. R., and Müller, N., “A Review of Wave Rotor Technology and Recent Developments,” J. Engineering for Gas Turbines and Power, Vol. 128, No. 4, 2006, pp. 717-735.

4. Zauner, E., Chyou, Y. P., Walraven, F., and Althaus, R., "Gas Turbine Topping Stage Based on Energy Exchangers: Process and Performance,” ASME Paper 93-GT-58, International Gas Turbine Congress, Cincinnati, OH, 1993.

5. Paxson, D. E., Wilson, J., and Welch, G. E., “Comparison Between Simulated and Experimentally Measured Performance of a Four Port Wave Rotor,” NASA/TM-2007-214985, ARL-TR-4202, AIAA Paper-2007-5049, 43rd Joint Propulsion Conference, Cincinnati, OH, 2007.

6. Welch, G. E., Paxson, D. E., Wilson, J., and Snyder, P. H., "Wave-Rotor-Enhanced Gas Turbine Engine Demonstrator,” NASA/TM-1999-209459, ARL-TR-2113, Gas Turbine Operation and Technology for Land, Sea and Air Propulsion and Power Systems Symposium, NATO, Ottawa, Canada, 1999.

7. Weber, R, “A Pressure-Wave Machine with Integrated Constant-Volume Combustion,” Swiss Energy Research Report 1977-1997, National Foundation for Energy Research, Berne, Switzerland, Project No. 426, pp. 142153.

8. Akbari, P., Nalim, M. R., and Müller, N., “A Review of Wave Rotor Technology and Recent Developments,” J. Engineering for Gas Turbines and Power, Vol. 128, No. 4, 2006, pp. 717-735.

9. Akbari, P., and Nalim, M. R., "Review of Recent Developments in Wave Rotor Combustion Technology,” J. Propulsion and Power, Vol. 25, No.4, 2009, pp. 833-844.

10. Nalim, M. R., “Assessment of Combustion Modes for Internal Combustion Wave Rotors," Journal of Engineering for Gas Turbines and Power, Vol. 121, No. 2, 1999, pp. 265-271.

11. Nalim, M. R., and Paxson, D. E., “A Numerical Investigation of Premixed Combustion in Wave Rotors,” Journal of Engineering for Gas Turbines and Power, Vol. 119, No. 3, 1997, pp. 668-675. 
12. Nalim, M. R., “Longitudinally Stratified Combustion in Wave Rotors,” Journal of Propulsion and Power, Vol. 16, No. 6, 2000, pp. 1060-1068.

13. Snyder, P. H., Alparslan, B., and Nalim, M. R., "Wave Rotor Combustor Test Rig Preliminary Design,” ASME Paper IMECE2004-61795, International Mechanical Engineering Congress, Anaheim, CA, 2004.

14. Akbari, P., Nalim, M.R., and Snyder, P.H., "Numerical Simulation and Design of a Combustion Wave Rotor for Deflagrative and Detonative Propagation,” AIAA Paper 2006-5134, 42nd Joint Propulsion Conference, Sacramento, CA, 2006.

15. Paxson, D.E., “A General Numerical Model for Wave Rotor Analysis,” NASA TM-105740, 1992.

16. Paxson, D.E., “Comparison Between Numerically Modeled and Experimentally Measured Wave-Rotor Loss Mechanisms,” Journal of Propulsion and Power, Vol. 11, No.5, 1995.

17. Paxson, D.E., “Numerical Simulation of Dynamic Wave Rotor Performance,” Journal of Propulsion and Power, Vol.12, No.5, 1996.

18. Elharis, T.M., “A Multi-step Reaction Model for Stratified-Charge Combustion in Wave Rotors,” M.S.Thesis, Indiana University-Purdue University Indianapolis, 2011.

19. Matsutomi, Y., Hein, C., Lian, C., Meyer, S., Merkle, C., and Heister, S., "Facility Development for Testing of Wave Rotor Combustion Rig,” AIAA 2007-5052, 43rd Joint Propulsion Conference, Cincinnati, OH, 2007.

20. Matsutomi, Y., Meyer, S., Wijeyakulasuriya, S.D., Izzy, Z., Nalim, M.R., Shimo, M., Kowalkowski, M., and Snyder, P.H., “Experimental Investigation on the Wave Rotor Constant Volume Combustor,” AIAA 2010-7043, 46 ${ }^{\text {th }}$ Joint Propulsion Conference, Nashville, TN, 2010.

21. Elharis, T.M., Wijeyakulasuriya, S.D., and Nalim, M.R., “Wave Rotor Combustor Aerothermodynamic Design and Model Validation based on Initial Testing,” AIAA 2010-704, 46th Joint Propulsion Conference, Nashville, TN, 2010.

22. Elharis, T.M., Wijeyakulasuriya, S.D., Nalim, M.R. and Matsutomi, Y., “Analysis of Deflagrative Combustion in a Wave-Rotor Constant-Volume Combustor,” AIAA 2011-583, 49 ${ }^{\text {th }}$ Aerospace Sciences Meeting, Orlando, FL, 2011.

23. Elharis, T. M., Wijeyakulasuriya, S. D., and Nalim, M. R., “A Two-Step Reaction Model for Stratified-Charge Combustion in Wave-Rotors,” AIAA-2011-5748, 47th Joint Propulsion Conference, San Diego, CA, July 2011. 
24. Snyder, P. H., Elharis, T. M., Wijeyakulasuriya, S. D., Nalim, M. R., Matsutomi, Y., and Meyer, S., “Pressure Gain Combustor Component Viability Assessment Based on Initial Testing,” AIAA-2011-5749, 47th Joint Propulsion Conference, San Diego, CA, July 2011.

25. Wijeyakulasuriya, S. D. and Nalim, M. R., "Fuel Proximity Effect on Hot-Jet Ignition in a Wave Rotor Constant Volume Combustor,” AIAA-2012-4171, 48th Joint Propulsion Conference, Atlanta, GA, 2012.

26. Smith, K. and Nalim, M. R., "Coupled Analysis of the Inlet and Fuel Systems of a Wave Rotor ConstantVolume Combustor,” AIAA-2012-4169, 48th Joint Propulsion Conference, Atlanta, GA, 2012.

27. Snyder P. H. and Nalim, M. R., “Wave Rotor Pressure Gain Combustion Rig Performance Assessment,” 33rd JANNAF Air-Breathing Propulsion Conference, Joint Army Navy NASA Air Force interagency propulsion committee Paper 2746, Monterey, CA, 2012.

28. Akbari, P., Nalim, M. R. , Donovan, E. S., and Snyder, P. H., “Leakage Assessment of Pressure-Exchange Wave Rotors,” J. Propulsion \& Power, vol. 24, no. 4, Jul-Aug 2008.

29. Spalding, D.B., "Mixing and Chemical Reaction in Steady Confined Turbulent Flames,” 13th Symposium (International) on Combustion, The Combustion Institute, 1971.

30. Ma, C. Y., Mahmud, T., Gaskell, P. H., and Hampartsoumian, E., "Numerical Predictions of a Turbulent Diffusion Flame in a Cylindrical Combustor using Eddy Dissipation and Flamelet Combustion Models,” Proceedings of the Institution of Mechanical Engineers, Part C: Journal of Mechanical Engineering Science July 1999, vol. 213 no. 7 pp. 697-705.

31. Ertesvåg, I.S. and Magnussen, B.F., “The Eddy Dissipation Turbulence Energy Cascade Model,” Combustion Science and Technology, Vol. 159, no. 1, pp. 213-235, 2000.

32. Wilcox, D.C., Turbulence Modeling for CFD , DCW Industries, La Canada, California, 1993.

33. Launder, B.E. and Spalding, D.B., “The Numerical Computation of Turbulent Flows,” Computer Methods in Applied Mechanics and Engineering, Vol. 3, No.2, 1974.

34. Kilchyk, V., Nalim, R., and Merkle, C., "Scaling Interface Length Increase Rates in Richtmyer-Meshkov Instabilities,” ASME Journal of Fluids Engineering, vol. 135, no. 3, 2013.

35. Kilchyk, V., Nalim, R., and Merkle, C., “Laminar Premixed Flame Fuel Consumption Rate Modulation by Shocks and Expansion Waves,” Combustion \& Flame, vol. 158, no. 6, pp. 1140-1148, Jun 2011. 
36. Kilchyk, V., Nalim, R., and Merkle, C., “Baroclinic Vortex Sheet Production by Shocks and Expansion Waves,” Shock Waves, vol. 20, no. 5, pp. 367-380, Oct 2010.

37. Wijeyakulasuriya, S. D., Rajagopal, M., and Nalim, M. R., "Shock-Flame Interaction Modeling in a ConstantVolume Combustion Channel, using Detailed Chemical Kinetics and Automatic Mesh Refinement,” ASME Paper GT2013-94617, International Gas Turbine Congress, San Antonio, TX, 2013.

38. Wijeyakulasuriya, S. D., Perera, I. U., and Nalim, M. R., "Mixing and Ignition Potential of a Transient Confined Turbulent Jet in a Wave Rotor Constant-Volume Combustor,” paper AIAA 2010-7042, 46th Joint Propulsion Conference, Nashville, TN, 2010.

39. Karimi, A., Rajagopal, M., and Nalim, M. R., “Traversing Hot-Jet Ignition in a Constant-Volume Combustor,” ASME Journal of Engineering for Gas Turbines \& Power, Paper No: GTP-13-1325, vol. 136, No. 4, 041506 (8 pages), 2014.

40. Chinnathambi, P., Karimi, A., Rajagopal, M., and Nalim, M. R., “Experimental Study of Traversing Hot-Jet Ignition of Lean Hydrocarbon-Air Mixtures in a Constant-Volume Combustor,” paper 2C12, 8th US National Combustion Meeting, The Combustion Institute, 2013.

41. Karimi, A., Chinnathambi, P., Rajagopal, M., and Nalim, M. R., "Effect of Jet Composition in Hot Jet Ignition of Premixed Mixture in a Constant-Volume Combustor,” paper 2C09: 8th US National Combustion Meeting, The Combustion Institute, 2013.

42. Khan, Md N., Paik, K-Y, and Nalim, M. R., “Torch-Jet Ignition of Premixed Methane-Hydrogen-Air Blends in a Constant-Volume Combustor: 3D Computational Modeling,” paper AIAA 2015-3784, AIAA 2015 Propulsion \& Energy Forum, Orlando, FL, 2015. 